\title{
The Overlap Model: A Model of Letter Position Coding
}

\author{
Pablo Gomez \\ DePaul University
}

\author{
Roger Ratcliff \\ The Ohio State University
}

\author{
Manuel Perea \\ Universitat de València
}

\begin{abstract}
Recent research has shown that letter identity and letter position are not integral perceptual dimensions (e.g., jugde primes judge in word-recognition experiments). Most comprehensive computational models of visual word recognition (e.g., the interactive activation model, J. L. McClelland \& D. E. Rumelhart, 1981, and its successors) assume that the position of each letter within a word is perfectly encoded. Thus, these models are unable to explain the presence of effects of letter transposition (trial-trail), letter migration (beard-bread), repeated letters (moose-mouse), or subset/superset effects (faulty-faculty). The authors extend R. Ratcliff's (1981) theory of order relations for encoding of letter positions and show that the model can successfully deal with these effects. The basic assumption is that letters in the visual stimulus have distributions over positions so that the representation of one letter will extend into adjacent letter positions. To test the model, the authors conducted a series of forced-choice perceptual identification experiments. The overlap model produced very good fits to the empirical data, and even a simplified 2-parameter model was capable of producing fits for 104 observed data points with a correlation coefficient of .91
\end{abstract}

Keywords: lexical process, letter position coding, word recognition, modeling, perceptual matching

A fundamental issue for any computational model of visual word recognition is how to represent the position in which letters are encoded. If letter position is not encoded, then anagrams like causal and casual or even desserts and stressed would not be able to be discriminated from each other. Some of the current computational models of visual word recognition make overly simplistic assumptions about how letter positions are coded, for example, that positions are perfectly encoded.

The way in which letter positions are encoded needs to be a critical aspect of the front end of any computational model of visual word recognition. Letter position determines which words are considered orthographically similar and, therefore, which word representations are most likely to be selected for a particular string of letters. It also determines which words are likely to be confused with each other, especially when the stimulus is impoverished. Although the encoding of letter position has not been a primary concern of visual word-recognition models, there have been models across a range of domains that focus on the relationship

Pablo Gomez, Psychology Department, DePaul University; Roger Ratcliff, Department of Psychology, The Ohio State University; Manuel Perea, Departmento de Metodología, Universitat de València, València, Spain.

This research was supported by National Institute of Mental Health Grants R37-MH44640 and K05-MH01891 to Roger Ratcliff, Spanish Ministry of Education and Science Grant SEJ2005-05205/EDU to Manuel Perea, and National Science Foundation Grant SES-0446869 to Pablo Gomez. We thank Colin Davis, Rebecca Johnson, and Sarah White for their comments.

Correspondence concerning this article should be addressed to Pablo Gomez, DePaul University, Psychology Department, 2219 North Kenmore, Chicago, IL 60614. E-mail: pgomez1@condor.depaul.edu between the location (in terms of space or position in a list) and the identities of letters, words, or objects (e.g., Estes, 1975; Lee \& Estes, 1977; Logan, 1996; and in particular, Ratcliff, 1981). In this article, we apply Ratcliff's (1981) model of order relationships for letter strings to describe how letter positions are encoded and provide support for the model from data from a variety of experiments.

In the literature on visual word recognition, the most prominent computational model has been the interactive activation (IA) model (McClelland \& Rumelhart, 1981; Rumelhart \& McClelland, 1982) and its successors (e.g., dual-route cascaded [DRC] model, Coltheart, Rastle, Perry, Langdon, \& Ziegler, 2001; multiple readout model [MROM], Grainger \& Jacobs, 1996; MROM-p, Jacobs, Rey, Ziegler, \& Grainger, 1998; CDP + model, Perry, Ziegler, \& Zorzi, 2007; and other connectionist models, Seidenberg \& McClelland, 1989; Plaut, McClelland, Seidenberg, \& Patterson, 1996.). The IA model, DRC model, and MROM share the same assumptions about location-specific letter processing (the more recent connectionist models are discussed later). According to the IA model, words are represented as collections of the orthographic features contained within their letters. When a string of letters is presented, the representations of all the word units that are orthographically similar to the input are activated. Lateral inhibition among word units that share features causes them to inhibit each other, so that the strongest beats down its competitors. The most relevant aspect of the IA model to this article is its letter position coding scheme. Namely, letters are assumed to be tagged to their position in the perceived word, and each letter is processed independently within its own channel. According to the IA model, the word judge is as similar to the transposed-letter nonword jugde as to the nonword junpe because it matches in three out of five letters 
in both cases; however, intuition indicates that judge is more similar to the nonword jugde than to the nonword junpe.

\section{Position Coding Effects}

On the basis of the above example, it seems that the IA model's similarity estimates are incorrect. The evidence against the position coding scheme of the IA model goes beyond just intuition. Several decades ago, Bruner and O'Dowd (1958) noted that nonwords in which the internal adjacent letters are transposed (e.g., jugde, mohter) are often perceived as words. Indeed, there is empirical evidence that shows that the processing of adjacent transposed-letter words (e.g., trail-trial) requires more time than the processing of control words and that adjacent transposed-letter nonwords (e.g., jugde) are more difficult to classify as nonwords than one-letter-different pseudowords (e.g., judpe) or control pseudowords (e.g., slint; Andrews, 1996; Chambers, 1979; O’Connor \& Forster, 1981; Perea, Rosa, \& Gómez, 2005). Furthermore, using the masked priming technique (Forster \& Davis, 1984), adjacent transposed-letter nonword primes produce both form and associative priming effects relative to an orthographic control. For example, jugde primes judge more than jupte primes judge (Andrews, 1996; Forster, Davis, Schoknecht, \& Carter, 1987; Perea \& Lupker, 2003b; Schoonbaert \& Grainger, 2004) and jugde primes court (Perea \& Lupker, 2003a). The effects of string similarity due to letter transposition have also been found in normal reading when the participant's eye movements are monitored (Acha \& Perea, 2008a; Johnson, Perea, \& Rayner, 2007; Rayner, White, Johnson, \& Liversedge, 2006). Transposed-letter effects are not limited to adjacent letters. Perea and Lupker (2004) found sizeable masked priming effects from transposed-letter nonwords to the words from which they were created when two noncontiguous interior letters were transposed (e.g., caniso-casino vs. caviro-casino). Clearly, the position-specific coding scheme used by the IA model has great difficulty explaining such transposed-letter effects.

Another weakness of the coding scheme in the IA model is that it does not assign a special role to any letter position. It is well known, however, that the quality of position information is better for letters at the beginning of the word (and sometimes at the end) than for internal letters (e.g., Estes, Allmeyer, \& Reder, 1976; Jordan, 1990; Perea, 1998). For example, pairs of words that differ in an internal position (e.g., woven-women) produce larger priming effects than pairs of words that differ in an end position (e.g., reach-react; Perea, 1998), and a number of experiments have reported greater transposed-letters similarity effects for items in which middle or internal letters are transposed (Chambers, 1979; Holmes \& Ng, 1993; Perea \& Lupker, 2003a).

In sum, letter positions do not seem to be assigned precisely and automatically in word processing. As Davis (1999) pointed out, the IA model and the models that use the same coding scheme are falsified by the existence of transposed-letters effects. These issues were discussed by Rumelhart and McClelland (1982, p. 89); in the second of their two articles on the IA model, they pointed out that there might be regions of uncertainty associated with each letter. This would lead to partial activation of letters from nearby positions relative to where the stimulus was actually presented. The implementation of a coding scheme with a noisy visual code would cause transposed-letter errors (e.g., jugde being recognized as the word judge). Similarly, Rumelhart and McClelland also indicated that some letter positions (i.e., external letters) could be more important than others. In this case, transposed-letter effects in the IA model would be a consequence of perceptual factors rather than orthographic coding. This would be consistent with a number of studies that have shown that perceptual processes involved in letter identification do not always provide precise information regarding letter location (e.g., Allport, 1977; Estes, 1975; Lee \& Estes, 1977; Mozer, 1983; Ratcliff, 1981). However, to our knowledge, location noise has not been implemented in the IA model. As Davis (1999) pointed out, because of the reliance on bottom-up inhibition in the IA model, a noisy visual input may harm the model's ability to recognize familiar inputs.

One alternative to channel-specific coding schemes is to use context-sensitive encoding, such as with the Wickelfeature scheme of the connectionist model of Seidenberg and McClelland (1989; see also Mozer, 1987, for a similar coding scheme using letter clusters). In this model, the basic unit is not the single letter but a group of ordered letters. For instance, the codes for trail would be _tr, tra, rai, ail, and $i l_{-}$, where the sign _ refers to the end of the letter string. This coding scheme cannot explain transposed-letter effects, for example, the transposed-letter words trail and trial would match in only one out of five Wickelfeatures (_tr). In contrast, trail and train would match in three Wickelfeatures (_tr, tra, and rai). Plaut et al. (1996), in a revision of the Seidenberg and McClelland model, recognized the limitations of the Wickelfeature approach. Their main concern was not orthographic processing but reading aloud; hence, they proposed syllabic position coding based on articulation components (onset, vowel, and coda). As Andrews (1996) pointed out, Plaut et al.'s model cannot predict the transposition effects when transpositions occur across an onset-vowel or vowel-coda boundary, as is the case for the majority of transposed-letters word pairs.

In the past few years, new models of word identification with a letter position coding mechanism have been proposed (e.g., the SERIOL model, Whitney, 2001; the open-bigram model, Grainger \& van Heuven, 2003; and the SOLAR model, Davis, 1999, 2002). We examine them in more detail in the general discussion. For now, we present the rationale and principles of the overlap model.

\section{Position Uncertainty}

The overlap model presented in this article is a model of letter position coding that applies Ratcliff's $(1981,1985,1987)$ theory of order relationships to data from a number of experiments in which orthographic similarity between two letter strings was manipulated. The basic assumption of the model is that locations of objects (in our case, letters) are best understood as distributions along a dimension (in our case, position in the string), rather than as precise points. This assumption is shared with other models, such as, for example, the CODE model (Compton \& Logan, 1993; Logan, 1996; Van Oeffelen \& Vos, 1982, 1983) and the model of Ashby, Prinzmetal, Ivry, and Maddox (1996).

The CODE model of perceptual grouping assumes that there are two representations of space. The first is an analogue representation of the location of items in which these locations are distributed 
symmetrically $^{1}$ along a spatial dimension or dimensions. The second is a quasi-analogue, quasi-discrete representation of groups of objects based on the sum of the location of items. Perceptual groups represent peaks above a threshold; Van Oeffelen and Vos $(1982,1983)$ showed that this could explain well-known perceptual grouping effects. To summarize, the CODE model tries to integrate space-based and object-based approaches. Location is distributed in the sense that information about the features of the items is distributed over space. The height of a distribution at any point in space represents probability of sampling features of the item it represents. Note that, in the overlap model, we focus on the area under the curve rather than on the height, but the idea of sampling letter features is similar in spirit to the CODE model. Maddox, Prinzmetal, Ivry, and Ashby (1994) and Ashby et al. (1996) used the principle of position uncertainty to account for perceptual phenomena. In a task in which participants estimated the distance between two objects, Maddox et al. explained performance by assuming that there is uncertainty in the positions of the objects. Similarly, Ashby et al. used the same principle to account for feature binding in object perceptions, as well as illusory conjunctions of the type described by Treisman and Schmidt (1982).

These ideas about position uncertainty can be taken into account by models of visual word recognition to address the now wellknown problem of the position-specific letter coding. For example, the original implementation of the Bayesian reader model (Norris, 2006) assumes position-specific letter coding. However, Norris (2006) also indicated that "even incorporating a separate level of letter representations does not alter the behavior of the [Bayesian reader] model" (p. 347). Along the same lines, Norris and Kinoshita (2007) recently pointed out that the Bayesian reader model might be compatible with a front-end model of letter position coding like the one proposed in this article.

\section{The Overlap Model}

In the model presented in this article, the identities of the letters in any string of letters are assumed to be normally distributed over position. For instance, if the string of letters is the word trail, the letter $a$ will be associated with Position 3 but also, to a lesser degree and depending on the size of the standard deviation, to Positions 2 and 4 and even to Positions 1 and 5 (see top three panels in Figure 1). Each letter position has a different standard deviation, which is treated as a free parameter in the model. The model assumes that a test string that is presented unmasked and for an unlimited viewing time can produce accurate location coding (bottom panel of Figure 1), while strings that are presented briefly have distributions over letter position.

This assumption of position uncertainty allows the overlap model to capture a number of the well-known effects reported in the literature on visual word recognition. The model can readily accommodate the presence of transposed-letters effects when the transposed letters are adjacent, for example, trail and its transposed-letter neighbor trial, overlap in Positions 3 and 4, depending on the standard deviation of the third and fourth letter positions, as is shown in the second panel of Figure 1. When the stimuli are trail and train, there is no letter match in the fifth position, as shown in the top panel of Figure 1. Furthermore, the model can readily account for the finding that transposed-letter similarity effects can be found when the transposed letters are

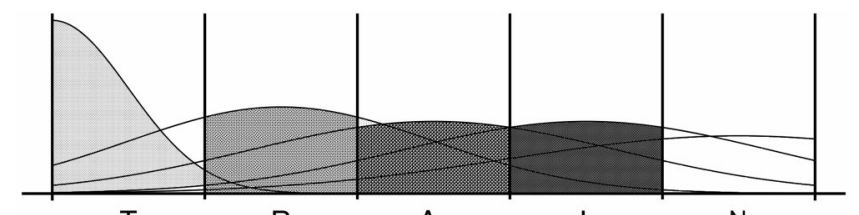

$\mathrm{T}$

$\mathrm{R}$

A

I

N

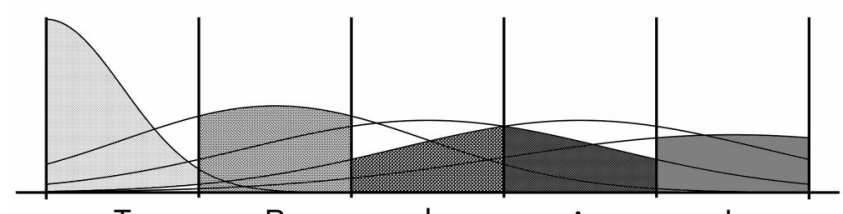

T

$\mathrm{R}$

I

A

$\mathrm{L}$
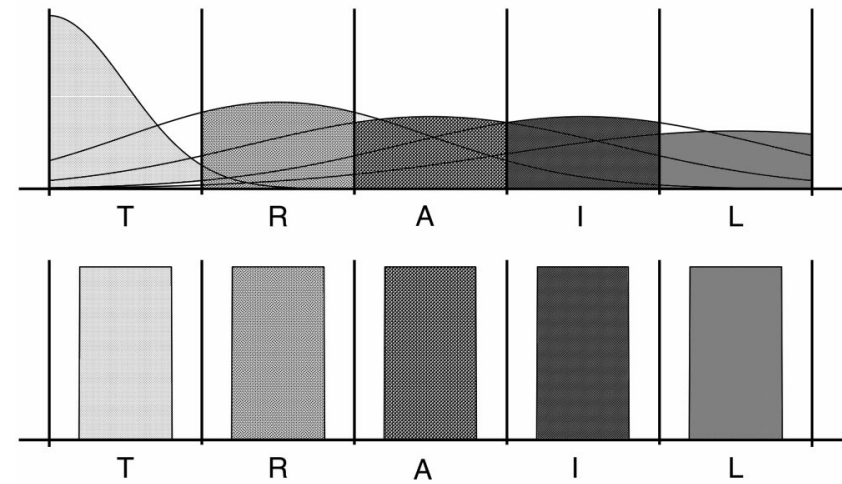

Figure 1. The figure shows a representation of the encoding of letter position according to the overlap model. The shaded areas represent the overlap between the string TRAIL (bottom panel) and three possible flashed strings: TRAIN, TRIAL, and TRAIL.

noncontiguous; for example, in the overlap model, caniso and casino will be more similar to each other than casino and its two-replacement-letter control caviro (Johnson, 2007; Perea \& Lupker, 2004; Ratcliff, 1981). Finally, the model can readily account for the finding that the first letter is more important than interior letters because in fits of the model to data, the standard deviation in the internal letter positions is larger than the standard deviation in the first position (Chambers, 1979; Johnson et al., 2007; Perea \& Lupker, 2003a, 2003b; Ratcliff, 1981).

The overlap model was originally applied to data from the perceptual matching task with manipulations of letter replacements and letter transpositions from study to test (Ratcliff, 1981, 1985, 1987; Ratcliff \& Hacker, 1981; see also Krueger, 1978; Proctor \& Healy, 1985, 1987). In this article, in addition to transposition/ replacement manipulations, we also examine the effect of letter repetition and changes in the number of letters in the strings between study and test. The perceptual matching task is not ideal for studying these manipulations because the 1-s study time would allow participants to notice a repetition or count the number of letters in the study string and use this information instead of the encoded representation of the letter string to make their decision.

${ }^{1}$ Logan's (1996) CODE model uses Laplace distributions, but Van Oeffelen and Vos (1982) and the overlap model assume that the distributions are normal. The choice of distribution is unlikely to have a major effect in the predictions of these models, as long as they are symmetrical distributions. 
Thus, we chose a paradigm that allows a full examination of combinations of letter transpositions and replacements, letter repetitions, and small changes in word length while avoiding (or reducing) the possibility that participants will adopt alternative strategies. To accomplish these aims, we chose a forced-choice perceptual identification paradigm (Ratcliff \& McKoon, 1997; Ratcliff, McKoon, \& Verwoerd, 1989). In this task, participants are presented with a stimulus letter string typically for $10-80 \mathrm{~ms}$, followed by a mask and then two test letter strings. The participant's task is to decide which of the two test strings was presented. Because the stimulus string is presented briefly and masked, it is difficult for a participant to determine whether letters are repeated or to count the length of the string. We chose an encoding time (60 $\mathrm{ms}$ ) that is in the range of values that produce reasonably accurate single-letter discrimination (Ratcliff \& Rouder, 2000; Thapar, Ratcliff, \& McKoon, 2003). It is also in the range of time of foveal encoding needed for almost full word encoding in reading (Rayner, Inhoff, Morrison, Slowiaczek, \& Bertera, 1981; Rayner, Liversedge, White, \& Vergilino-Perez, 2003; Rayner \& Pollatsek, 1981; but see White, Johnson, Liversedge, \& Rayner, in press, for a discussion of parafoveal effects). It is reasonable to assume that the position uncertainty of letters is reduced over time and that distributions over position represent only the initial encoding processes in reading.

When two strings of letters are compared, the overlap model assumes that an amount of orthographic similarity is computed from the overlap between the two strings. In our paradigm, the test string is assumed to have letters exactly located in the correct position (see Figure 1, bottom panel); the letters are continuously visible at test in the forced-choice paradigm until the decision is made. To measure the amount of overlap between a study stimulus and one of the test stimuli, for each position, the area under the curve of the letter in the test string in the slot is multiplied by the area of the same letter in corresponding slot for the study string, and these products are summed over all the slots. In the case of five-letter strings, the overlap is

$$
o=\sum_{i=1}^{5} \int_{i-1 / 2}^{i+1 / 2} f_{1}(x) d x \int_{i-1 / 2}^{i+1 / 2} f_{2}(x) d x,
$$

where $i$ is the center of the position slot, $f_{1}(x)$ is the distribution of the first stimulus centered on $i, f_{2}(x)$ is the distribution of second stimulus, and $x$ is the position along the spatial axis (see Figure 1).

For the two-alternative forced-choice task, the model computes the amount of overlap between the target stimulus and each of the two alternatives (i.e., the target stimulus with the correct alternative $\left[o_{t}\right]$ and the target stimulus with the foil $\left.\left[o_{f}\right]\right)$. This measure of overlap between the target stimulus and the two alternatives is transformed into correct response proportions using a power function as in Nosofsky and Palmeri (1997) and Ratcliff (1981). The response probability for the correct alternative is

$$
p(\text { correct })=o_{t}^{a} /\left(o_{t}^{a}+o_{f}^{a}\right),
$$

where $a$ is a scaling parameter. The parameter $a$ is greater than 1 , and this allows small differences in overlap to produce larger effects in accuracy. In the experiments presented below, the empirical response proportions were compared with the fits of the six-parameter model. Large correct response proportions indicate smaller similarity between the two test strings, and vice versa.

In the rest of this article, we focus on the model's fits to experimental data and leave the details of the empirical results for Appendix A. In the General Discussion, we discuss how the overlap model might be used as a front end for models of visual word recognition, and we compare the predictions of the overlap model with those from other more recent competing computational models (e.g., SERIOL model, Whitney, 2001, in press; SOLAR model, Davis, 1999, 2002; open-bigram model, Grainger \& van Heuven, 2003). Given the importance of the masked priming technique in this area of research, we have included Appendix B to show how the overlap model might address the results of a number of manipulations of letter order in the prime letter string from masked priming studies.

\section{Overview of the Experiments and General Method}

We present five experiments in which we used a two-alternative forced-choice paradigm. On each trial, a target stimulus was presented for $60 \mathrm{~ms}$ on the center of the computer screen, and then it was subsequently masked with segments of letters. The participant had to choose between two alternatives that were presented simultaneously below the mask (one to the right and the other to the left of the mask, as can be seen in Figure 2).

In the experiments, we used six different types of foils: (a) foils in which two letters were transposed, (b) foils in which one letter was replaced, (c) foils in which two letters were replaced, (d) foils in which one letter was duplicated, (e) foils in which one letter migrated from its original position, and (f) foils in which one letter was added to or taken away from the stimulus. We also examined the role of the lexical status of the target stimulus and the alternatives (i.e., word vs. nonword). Brief descriptions of the conditions and types of foils used in each of the experiments are presented in Table 1, and a more detailed description of the materials is presented in Appendix A.

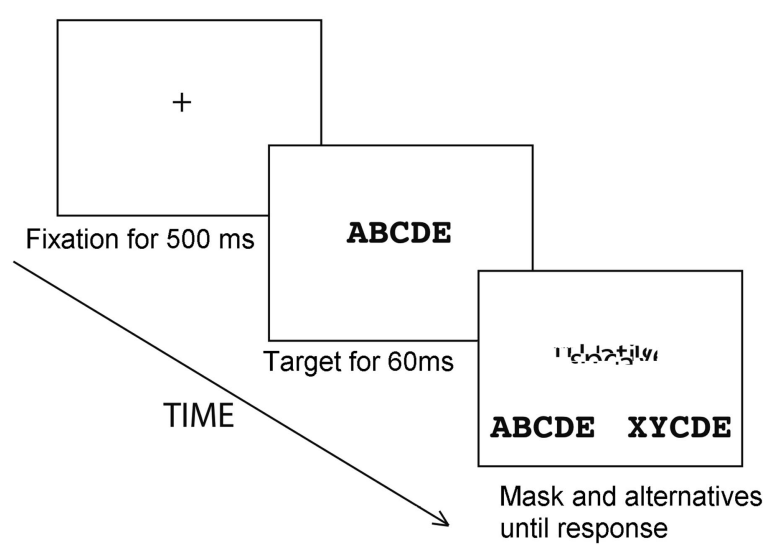

Figure 2. The figure represents a trial in the experiments presented in this article. First, there is a fixation point on the screen for $500 \mathrm{~ms}$, then the target is flashed for $60 \mathrm{~ms}$, and then the target is masked and two alternatives are presented. The participant is asked to choose which of the two alternatives was flashed. 
Table 1

Types of Items for the Five Experiments

\begin{tabular}{|c|c|c|c|c|c|c|c|c|}
\hline \multirow{2}{*}{\multicolumn{2}{|c|}{ Alternatives }} & \multirow[b]{2}{*}{ Type } & \multicolumn{6}{|c|}{ Experiment } \\
\hline & & & $1 \mathrm{a}$ & $1 \mathrm{~b}$ & 2 & 3 & 4 & 5 \\
\hline \multirow[t]{49}{*}{$\mathrm{ABCDE}$} & $\mathrm{XBCDE}$ & Single replacements & $\mathrm{NN}$ & & WN & $\mathrm{NN}$ & & \\
\hline & $\mathrm{AXCDE}$ & & NN & $\mathrm{NN}$ & WN & NN & NN & $\mathrm{NN}$ \\
\hline & ABXDE & & NN & $\mathrm{NN}$ & WN & NN & NN & NN \\
\hline & ABCXE & & NN & NN & WN & NN & NN & NN \\
\hline & ABCDX & & $\mathrm{NN}$ & $\mathrm{NN}$ & WN & $\mathrm{NN}$ & $\mathrm{NN}$ & NN \\
\hline & BACDE & Adjacent transpositions & $\mathrm{NN}$ & $\mathrm{NN}$ & WN; WW & $\mathrm{NN}$ & & $\mathrm{NN}$ \\
\hline & ACBDE & & NN & $\mathrm{NN}$ & WN; WW & NN & NN & NN \\
\hline & $\mathrm{ABDCE}$ & & NN & NN & WN; WW & NN & NN & NN \\
\hline & ABCED & & NN & $\mathrm{NN}$ & WN; WW & $\mathrm{NN}$ & $\mathrm{NN}$ & $\mathrm{NN}$ \\
\hline & $\mathrm{XYCDE}$ & Adjacent double replacements & NN & & WN & & & \\
\hline & AXYDE & & NN & $\mathrm{NN}$ & WN & & & \\
\hline & ABXYE & & NN & NN & WN & & & \\
\hline & $\mathrm{ABCXY}$ & & $\mathrm{NN}$ & $\mathrm{NN}$ & WN & & & \\
\hline & CBADE & Nonadjacent transpositions & $\mathrm{NN}$ & & WN; WW & & $\mathrm{NN}$ & \\
\hline & ADCBE & & NN & NN & WN; WW & & NN & \\
\hline & ABEDC & & NN & $\mathrm{NN}$ & WN; WW & & NN & \\
\hline & DBCAE & & NN & & WN; WW & & & \\
\hline & AECDB & & NN & $\mathrm{NN}$ & WN; WW & & $\mathrm{NN}$ & \\
\hline & XBYDE & Nonadjacent double replacements & $\mathrm{NN}$ & & WN & & & \\
\hline & AXCYE & & NN & NN & WN & & & \\
\hline & ABXDY & & NN & NN & WN & & & \\
\hline & XBCYE & & NN & & WN & & & \\
\hline & AXCDY & & $\mathrm{NN}$ & $\mathrm{NN}$ & WN & & & \\
\hline & BCADE & Letter migration & & & & $\mathrm{NN}$ & & \\
\hline & ACDEC & & & & & NN & & \\
\hline & CABDE & & & & & NN & & \\
\hline & ABDEC & & & & & NN & & \\
\hline & $\mathrm{ADBCE}$ & & & & & NN & & \\
\hline & ABECD & & & & & NN & & \\
\hline & AEBCD & & & & & NN & & \\
\hline & BCXCD & Migration + replacement & & & & $\mathrm{NN}$ & & \\
\hline & ACDXE & & & & & NN & & \\
\hline & XABDE & & & & & NN & & \\
\hline & ABDEX & & & & & NN & & \\
\hline & AXBCE & & & & & NN & & \\
\hline & $\mathrm{ABXCD}$ & & & & & NN & & \\
\hline & $\mathrm{AXBCD}$ & & & & & NN & & \\
\hline & $\mathrm{ABBDE}$ & Letter repetitions in one alternative & & & & & NN 2 & \\
\hline & $\mathrm{ABCCE}$ & & & & & & NN 2 & \\
\hline & $\mathrm{ABCDD}$ & & & & & & NN 2 & \\
\hline & ABADE & & & & & & NN 2 & \\
\hline & ABCBE & & & & & & NN 2 & \\
\hline & $\mathrm{ABCDC}$ & & & & & & NN 2 & \\
\hline & $\mathrm{ABCDB}$ & & & & & & NN 2 & \\
\hline & AXBCDE & Letter insertions & & & & & & $\overline{\mathrm{NN} 2}$ \\
\hline & $\mathrm{ABXCDE}$ & & & & & & & NN 2 \\
\hline & ABCXDE & & & & & & & NN 2 \\
\hline & ABCDXE & & & & & & & NN 2 \\
\hline & ABCDEX & & & & & & & NN 2 \\
\hline ABBDE & ADBBE & Letter repetitions in the two alternatives & & & & & NN 2 & \\
\hline $\mathrm{ABCCE}$ & $\mathrm{ACCBE}$ & & & & & & NN 2 & \\
\hline $\mathrm{ABCDD}$ & ABDDC & & & & & & NN 2 & \\
\hline ABADE & BADAE & & & & & & NN 2 & \\
\hline ABCBE & ACBEB & & & & & & NN 2 & \\
\hline $\mathrm{ABCDC}$ & $\mathrm{ACBCD}$ & & & & & & NN 2 & \\
\hline
\end{tabular}

Note. The marked cells in the table indicate whether a given condition was utilized in the experiment. NN indicates that the two alternatives were nonwords; WN indicates that one alternative was a nonword and the other was an English word; WW indicates that the two alternatives were English words. In Experiments 4 and 5, the conditions marked with NN 2 indicate that there were two different conditions for the two alternatives. For instance, when the alternatives differed by a letter insertion, like ABCDE and ABXCDE, the target could be either ABCDE or ABXCDE, and these were different conditions. In other cases, such as letter replacement/s, we collapsed across target identity; for instance, if the alternatives were $\mathrm{ABCDE}$ and $\mathrm{ABXDE}$, the target could be either of the two alternatives. 


\section{Experiments 1a and 1b: Transposed-Letter Effects With Nonword Stimuli}

In Experiments 1a and 1b, we focused on the discrimination between two English-like nonwords, one of which was the same as the flashed stimulus and the other either had two letters transposed or had either one or two letters replaced with other letters (consonants were replaced with other consonants, and vowels were replaced with other vowels). We also manipulated the letter positions for the transpositions and replacements (adjacent letter positions, or nonadjacent letter positions for the two-letter transpositions and replacements). We used nonwords to have enough stimuli in all conditions because there are relatively few words that transpose to words and fewer still for each pair of letter positions in a word. Given the near-ceiling performance in the conditions in which the initial letter was manipulated in Experiment 1a, in Experiment $1 \mathrm{~b}$, we reduced the number of conditions in which the initial letter was manipulated (see Table 1 and Appendix A for a description of the materials and method). In Experiment 1b, we kept the condition with the transposition of first and second letters to provide one condition in which the first letter position changes to help modeling.

\section{Results and Modeling}

The results indicate that adjacent letter transpositions were more difficult to discriminate than nonadjacent transpositions, transpositions were more difficult than replacements, and single replacements were more difficult than double replacements but not as difficult to discriminate as adjacent transpositions. Also, there was an advantage of the initial letter position (see Appendix A).

To fit the overlap model to the data, we minimized the sum of squares using a nonlinear least squares minimizing routine (Bates \& Chambers, 1992) that adjusts the values of the six parameters of the model. The data entered into the minimization routine were the response proportions for each of the 23 conditions averaged across participants for Experiment 1a and the 17 conditions for Experiment $1 \mathrm{~b}$. The predictions of the model with the best fitting parameters are presented in Table 2. Figure 3 shows the empirical data and the fits of the model for each condition. The circles represent the empirical data, the error bars represent two standard errors calculated from the data across participants, and the triangles represent the prediction of the overlap model. The open symbols represent transpositions, and the filled symbols represent replacements.

The model fits the patterns of data modestly well, with 30 of the 40 predicted points within two standard errors of the empirical results (see Figure 3). In Experiments $1 \mathrm{a}$ and $1 \mathrm{~b}$, the model predicted that the conditions with the final letters transposed (transposition of the fourth and fifth letters) would have lower discriminability than it actually did. In addition, the model underestimated the proportions of correct responses for the single replacement of the second and third letters. In spite of these misses, the model does provide a reasonable account of the pattern of data as a whole.

The best fitting parameters for all experiments are presented in Table 3 . The parameters $s_{1}$ to $s_{5}$ refer to the standard deviations of the letter distribution functions ( $s_{i}$ corresponds to the $i$ th position), and the parameter $a$ represents the power to which the match is
Table 2

Results From Experiments $1 \mathrm{a}$ and $1 \mathrm{~b}$

\begin{tabular}{|c|c|c|c|c|}
\hline \multirow[b]{2}{*}{ Conditions } & \multicolumn{2}{|c|}{ Transpositions } & \multicolumn{2}{|c|}{ Replacements } \\
\hline & $M(2 S E \mathrm{~s})$ & Model & $M(2 S E \mathrm{~s})$ & Model \\
\hline \multicolumn{5}{|c|}{ Experiment 1a } \\
\hline 1 and 2 & $.906(.029)$ & .889 & $.923(.037)$ & .971 \\
\hline 2 and 3 & $.625(.042)$ & .611 & $.826(.058)$ & .848 \\
\hline 3 and 4 & $.576(.041)$ & .570 & $.768(.049)$ & .797 \\
\hline 4 and 5 & $.606(.025)$ & .537 & $.749(.060)$ & .747 \\
\hline 1 and 3 & $.922(.033)$ & .953 & $.935(.028)$ & .967 \\
\hline 2 and 4 & $.704(.051)$ & .713 & $.783(.050)$ & .808 \\
\hline 3 and 5 & $.675(.045)$ & .688 & $.797(.045)$ & .792 \\
\hline 1 and 4 & $.912(.027)$ & .941 & $.936(.024)$ & .951 \\
\hline 2 and 5 & $.725(.043)$ & .773 & $.799(.045)$ & .803 \\
\hline 1 & & & $.927(.028)$ & .887 \\
\hline 2 & & & $.777(.052)$ & .689 \\
\hline 3 & & & $.733(.051)$ & .676 \\
\hline 4 & & & $.663(.050)$ & .626 \\
\hline 5 & & & $.657(.039)$ & .620 \\
\hline \multicolumn{5}{|c|}{ Experiment $1 \mathrm{~b}$} \\
\hline 1 and 2 & $.865(.041)$ & .870 & & \\
\hline 2 and 3 & $.626(.062)$ & .608 & $.840(.052)$ & .887 \\
\hline 3 and 4 & $.606(.049)$ & .594 & $.808(.065)$ & .870 \\
\hline 4 and 5 & $.658(.042)$ & .558 & $.807(.052)$ & .830 \\
\hline 2 and 4 & $.686(.064)$ & .705 & $.807(.060)$ & .843 \\
\hline 3 and 5 & $.749(.060)$ & .766 & $.852(.040)$ & .876 \\
\hline 2 and 5 & $.775(.054)$ & .808 & $.854(.034)$ & .850 \\
\hline 2 & & & $.798(.054)$ & .697 \\
\hline 3 & & & $.815(.042)$ & .734 \\
\hline 4 & & & $.720(.048)$ & .670 \\
\hline 5 & & & $.710(.057)$ & .679 \\
\hline
\end{tabular}

raised (see Equation 2). The best fitting values of the parameters are similar for Experiments 1a and 1b; the $s$ parameter increases as letter position increases. In Experiment 1a, there is a monotonic increase in the values of the $s$ parameter; in Experiment 1b, there is a slight decrease in value from $s_{2}$ to $s_{3}$ and also from $s_{4}$ to $s_{5}$. This suggests that the encoding of letter position is more accurate for the first letter than for the rest of the letters, while the last position does not seem to enjoy a special status with better spatial location for these nonword stimuli. This pattern is similar to that found by Ratcliff (1981) for the perceptual matching task.

\section{Experiment 2: Transposed-Letter Effects With Word Versus Nonword Target Stimuli}

While in Experiments 1a and 1b nonwords were used as stimuli, in Experiment 2 (see Appendix A) we used English words as targets, foils, or both. There were three types of trials: In wordnonword trials, the target stimulus was a word, and the foil was a nonword; in nonword-word trials, the target stimulus was a nonword, and the foil was a word; and in word-word trials, both the target stimulus and the foil were English words (e.g., salt-slat). The number of transposed-letters word-to-word pairs in English is relatively small; therefore, relatively few items were available for each condition in the word-word trials (see Table 1 for a brief description of the materials).

\section{Results and Modeling}

The details of the empirical results are presented in Appendix A. There was an effect of lexicality in which the accuracy is higher 


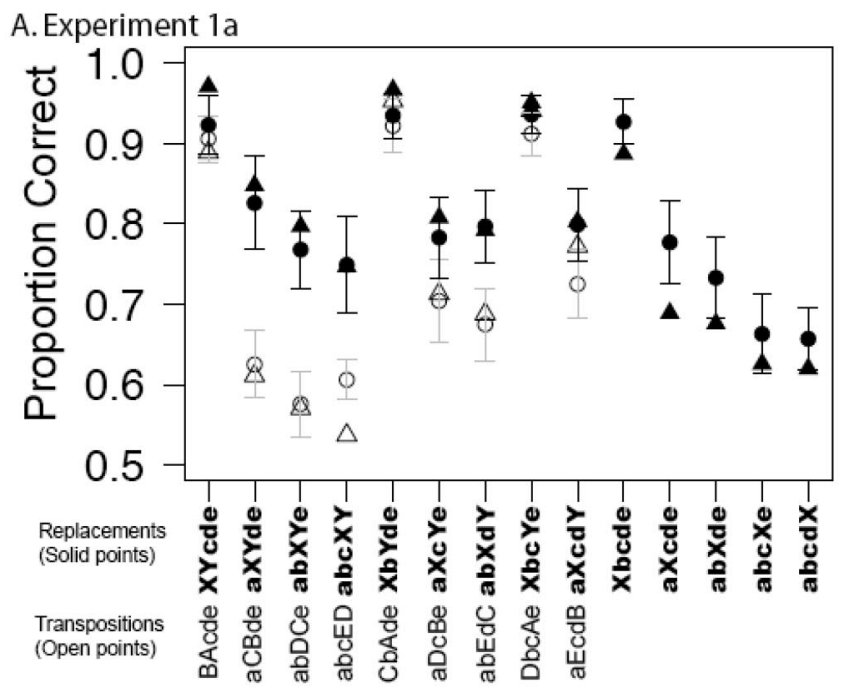

B. Experiment $1 \mathrm{~b}$

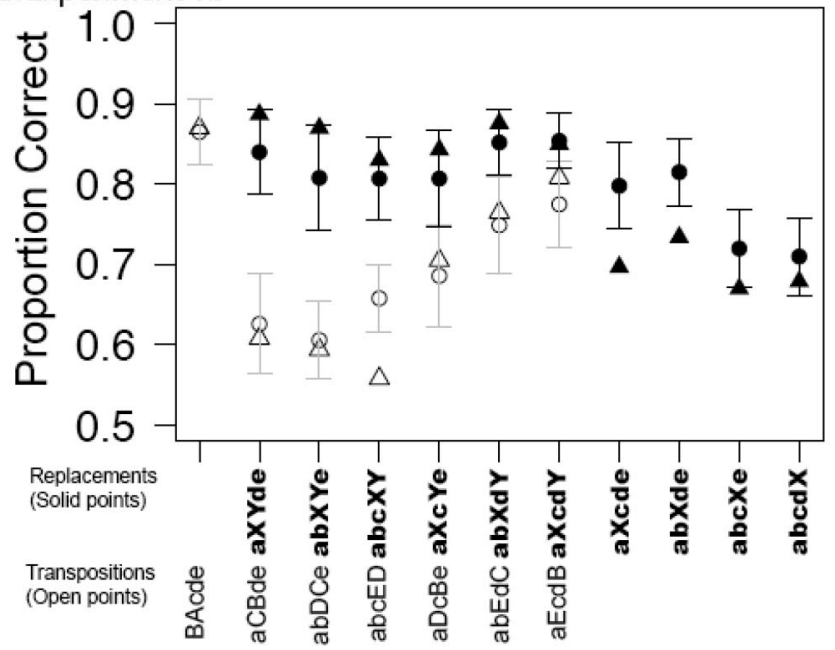

Figure 3. The figure shows the data and model fits for Experiments 1a (Panel A) and 1b (Panel B). The circles represent the data, and the triangle represents the model's fits. The different conditions are represented across the $x$-axis, and the proportion of correct responses is represented on the $y$-axis. Error bars indicate two standard errors of the mean.

for word-nonword trials (in which the word is the target) than for word-word trials, which in turn have higher accuracy than nonword-word trials (in which the nonword is the target). This demonstrates a bias for word targets. Even though the magnitude of the effects among the different conditions is reduced for wordnonword trials, the pattern (the relative sizes of accuracy differences over conditions) is very similar to the nonword-word trials; indeed, the pairwise correlations among the three types of trials and accuracy values from Experiment 1a are all over .90. This suggests that processing is similar regardless of the lexical status of the target/foil.

The data entered into the minimization routine were the response proportions for each of the 53 conditions. There were 23 transpositions/replacement conditions for word-nonword trials, 23 transposition/replacement conditions for word-nonword trials, and 7 transposition conditions for word-word trials (in this case, there were not enough pairs of words that produce long-range transpositions). The eight free parameters (see Table 3) for this experiment were three scaling parameters-one for words $(a)$, another for nonwords $(b)$, and a separate one for the word-word trials $\left(a_{w}\right)$ - and one set of five standard deviations $\left(s_{1}\right.$ to $\left.s_{5}\right)$. Equation 2 was changed to

$$
p(\text { correct })=o_{t}^{a} /\left(o_{t}^{a}+o_{f}^{b}\right),
$$

which was used for word-nonword trials, while, for nonwordword trials, the numerator in Equation 3 was $o_{t}^{b}$ and the denominator was $o_{t}^{a}+o_{f}^{b}$. In Equation 3, the difference between the $a$ and $b$ parameters allows differential response bias to words and nonwords; for example, assuming $a$ and $b$ to be $>1$, if $a>b$, the overlap between first alternative and the stimulus is scaled up to be larger (so the predicted proportion is larger) relative to the overlap between the second alternative and the stimulus. For word-word trials, Equation 2 was used because there was only one scaling exponent.

The predictions of the model with the best fitting parameters are presented in Table 4. Figure 4A shows the empirical data (circles) and the fits (triangles) of the model for each condition in the trials with word targets, while Figure 4B shows the fits for trials with nonword targets. The model accounts for the effect of lexical status of target and foil as well as for the effects of type of trial (transposed letters, single replacement letter, or double replacement letter). Although the qualitative pattern is adequately captured by the model, out of 53 data points in this experiment, 10 are outside the error bars, as can be seen in Figure 4. We carried out additional fits in which the $a$ and $b$ parameters were free to vary

Table 3

Parameters of the Model for All Experiments

\begin{tabular}{|c|c|c|c|c|c|c|}
\hline \multirow[b]{2}{*}{ Experiment } & \multicolumn{5}{|c|}{ Parameter } & \multirow[b]{2}{*}{ Exponent } \\
\hline & $s_{1}$ & $s_{2}$ & $s_{3}$ & $s_{4}$ & $s_{5}$ & \\
\hline $1 \mathrm{a}$ & 0.404 & 1.094 & 1.179 & 1.659 & 1.743 & 3.941 \\
\hline $1 b$ & 0.514 & 1.431 & 1.184 & 1.667 & 1.581 & 4.911 \\
\hline 2 & 0.499 & 1.204 & 1.158 & 1.295 & 1.131 & $\begin{aligned} a_{w} & =3.753 \\
a_{n} & =5.090\end{aligned}$ \\
\hline 3 & 0.488 & 1.420 & 1.336 & 1.384 & 1.453 & $\begin{array}{c}a_{w w}=6.220 \\
3.554\end{array}$ \\
\hline 4 & 0.778 & 1.674 & 1.461 & 1.578 & 1.509 & $\begin{array}{l}5.747 \\
7.866\end{array}$ \\
\hline 5 & 0.589 & 0.988 & 1.223 & 1.299 & 1.429 & 3.372 \\
\hline
\end{tabular}

Note. The three different exponents for Experiment 2 correspond to word alternatives $\left(a_{w}\right)$, nonword alternatives $\left(a_{n}\right)$, and word-word trials $\left(a_{w w}\right)$. The second exponent in Experiment 4 (7.866) corresponds to the option without repeated letters. The $s$ parameters belong to Equation 1:

$$
o=\sum_{i=1}^{5} \int_{i-1 / 2}^{i+1 / 2} f_{1}(x) d x \int_{i-1 / 2}^{i+1 / 2} f_{2}(x) d x .
$$

The exponents belong to Equation 2, when there is only one, and Equation 3 , when there is one exponent per alternative:

$$
p(\text { correct })=\frac{o_{t}^{a}}{\left(o_{t}^{a}+o_{f}^{a}\right)} .
$$


Table 4

Results From Experiment 2

\begin{tabular}{|c|c|c|c|c|}
\hline \multirow[b]{2}{*}{ Conditions } & \multicolumn{2}{|c|}{ Transpositions } & \multicolumn{2}{|c|}{ Replacements } \\
\hline & $M(2 S E s)$ & Model & $M(2 S E s)$ & Model \\
\hline \multicolumn{5}{|c|}{ Word target and nonword foil } \\
\hline 1 and 2 & $.913(.044)$ & .910 & $.916(.070)$ & .973 \\
\hline 2 and 3 & $.811(.064)$ & .784 & $.913(.054)$ & .919 \\
\hline 3 and 4 & $.777(.060)$ & .779 & $.886(.056)$ & .914 \\
\hline 4 and 5 & $.817(.062)$ & .781 & $.861(.056)$ & .916 \\
\hline 1 and 3 & $.932(.040)$ & .965 & $.949(.048)$ & .974 \\
\hline 2 and 4 & $.860(.062)$ & .865 & $.914(.048)$ & .911 \\
\hline 3 and 5 & $.880(.046)$ & .885 & $.938(.038)$ & .923 \\
\hline 1 and 4 & $.950(.032)$ & .968 & $.946(.052)$ & .970 \\
\hline 2 and 5 & $.883(.048)$ & .914 & $.912(.056)$ & .920 \\
\hline 1 & & & $.924(.054)$ & .924 \\
\hline 2 & & & $.884(.048)$ & .829 \\
\hline 3 & & & $.887(.044)$ & .833 \\
\hline 4 & & & $.849(.066)$ & .822 \\
\hline 5 & & & $.872(.042)$ & .835 \\
\hline \multicolumn{5}{|c|}{ Nonword target and word foil } \\
\hline 1 and 2 & $.877(.048)$ & .863 & $.938(.038)$ & .974 \\
\hline 2 and 3 & $.592(.086)$ & .528 & $.856(.054)$ & .881 \\
\hline 3 and 4 & $.457(.054)$ & .511 & $.836(.044)$ & .872 \\
\hline 4 and 5 & $.614(.094)$ & .520 & $.845(.070)$ & .875 \\
\hline 1 and 3 & $.933(.050)$ & .962 & $.956(.052)$ & .975 \\
\hline 2 and 4 & $.696(.066)$ & .758 & $.860(.058)$ & .866 \\
\hline 3 and 5 & $.724(.070)$ & .808 & $.842(.064)$ & .890 \\
\hline 1 and 4 & $.928(.044)$ & .967 & $.933(.062)$ & .971 \\
\hline 2 and 5 & $.759(.076)$ & .872 & $.824(.066)$ & .885 \\
\hline 1 & & & $.931(.054)$ & .893 \\
\hline 2 & & & $.772(.066)$ & .664 \\
\hline 3 & & & $.790(.060)$ & .674 \\
\hline 4 & & & $.722(.070)$ & .644 \\
\hline 5 & & & $.782(.066)$ & .681 \\
\hline \multicolumn{5}{|c|}{ Word target and word foil } \\
\hline 1 and 2 & $.937(.036)$ & .910 & & \\
\hline 2 and 3 & $.722(.036)$ & .650 & & \\
\hline 3 and 4 & $.653(.066)$ & .638 & & \\
\hline 4 and 5 & $.723(.052)$ & .643 & & \\
\hline 1 and 3 & $.940(.036)$ & .981 & & \\
\hline 2 and 4 & $.771(.160)$ & .826 & & \\
\hline 3 and 5 & $.808(.066)$ & .867 & & \\
\hline
\end{tabular}

across lexical status of the target, and we obtained slightly better fits.

The difference in proportion of correct responses was quite large between items for word trials and items for nonword trials, and this can be explained as a bias to select the word alternative (parameter $a$ for a word target was greater than parameter $b$ for a nonword target). Because the overlap model does not have an implemented lexicon, it is important to note that the word superiority effect found in this experiment is not, by itself, support for the overlap model. What we interpret as support for the model is that the same mechanism and the same $s$ parameters can account for the larger effects in word-word and nonword-word trials as well as the scaled-down effects in the word-nonword trials.

\section{Experiment 3: Letter Migrations}

In Experiments 1 and 2, we showed that the overlap model successfully captures the effect of transposed-letter similarity in the perceptual matching task. In this experiment, we examined another type of orthographic similarity effect: letter migration (see Appendix A). In the stimuli used for this experiment, one letter shifts two positions, and the other letters move one position to accommodate the shift. For example, in ABCDE versus ACDBE, the letter $\mathrm{B}$ in $\mathrm{ABCDE}$ moves from the second to the fourth position in ACDBE, and the letters $\mathrm{C}$ and $\mathrm{D}$ both move one position to the left. Because of the small number of word pairs that occur in English, we used wordlike nonword pairs (e.g., bealdbedal).

In sum, for a given nonword, the similar item could be (a) a transposed-letter item (in this experiment, we used only adjacent letter transpositions); (b) a single replacement item; (c) a lettermigration item, in which the $i$ th letter of one string goes to position $j$ in the other string and the other letters shift to accommodate the movement; and (d) an orthographic control, in which the migrated letter is replaced by a new letter (and the other two letters shift). Although this is not a perfect orthographic control, it adds condi-

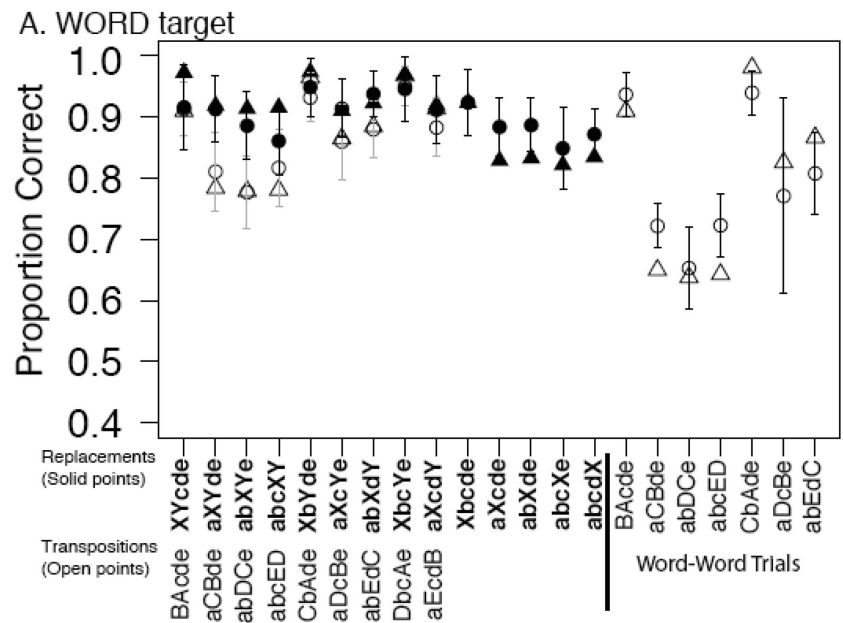

B. NONWORD target

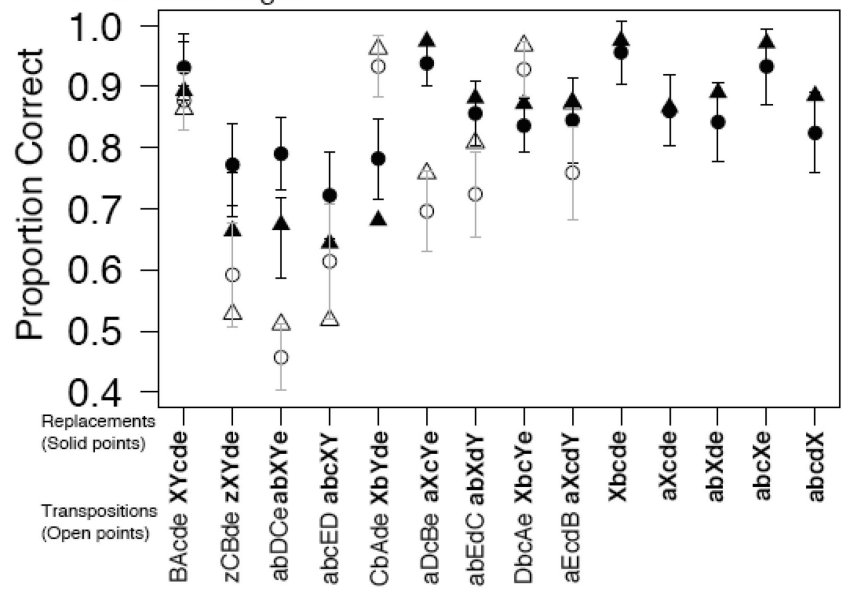

Figure 4. The figure shows the data and model fits for Experiment 2. A: Data and model fits for trials with word targets. B: Data and fits for trials with nonword targets. The circles represent the data, and the triangles represent the model's fits. The different conditions are represented across the $x$-axis, and the proportion of correct responses is represented on the $y$-axis. Error bars indicate two standard errors of the mean. 
tions for which the model has to account. As in Experiment $1 \mathrm{~b}$ and to limit the number of conditions that have near ceiling performance, most conditions in which the initial letter of the string could be manipulated were not used.

\section{Results and Modeling}

The procedure for fitting the overlap model was the same as in Experiment 1. The overlap model was fit to the data (circles in Figure 5), and 21 of the 23 predicted values from the model (triangles in Figure 5) fit within two standard errors of the data (see Figure 5 and Table 5). Thus, the model captures the effects of letter migration and the effects of transposition and replacement with no additional assumptions relative to the previous experiments.

The parameters of the model are similar to those in the previous experiments (see Table 3 ). The $s_{1}$ parameter is about .5 , which is slightly more than one third of the value of the other $s$ parameters (that range between 1.336 and 1.454). The scaling parameter ( $a$ parameter) has a value of 3.554 , which is slightly lower than the values for this parameter in the previous experiments with nonword targets.

\section{Experiment 4: Letter Repetition}

In this experiment (see Appendix A), we examined whether the overlap model can deal with items in which one of the letters is duplicated, for example, with a target ABCDE and a foil ABBDE or vice versa. This is an important issue because the effects of this manipulation might be problematic for some of the letter position coding models (e.g., the SOLAR and SERIOL models). We also added conditions with repeated plus migrated letters (e.g., target, $\mathrm{ABCCE}$, and foil, $\mathrm{ACCBE}$ ) to further test the model. Note again that the rapid presentation of the stimulus restricts or eliminates the strategy of basing the decision on whether the letters are repeated or not. There were conditions in which the target string included a repeated letter, conditions in which the foil included the repeated letter, and conditions in which both alternatives (the target and the foil) included a repeated letter. To add further constraints, adjacent transposed-letter and single replacement conditions were also included.

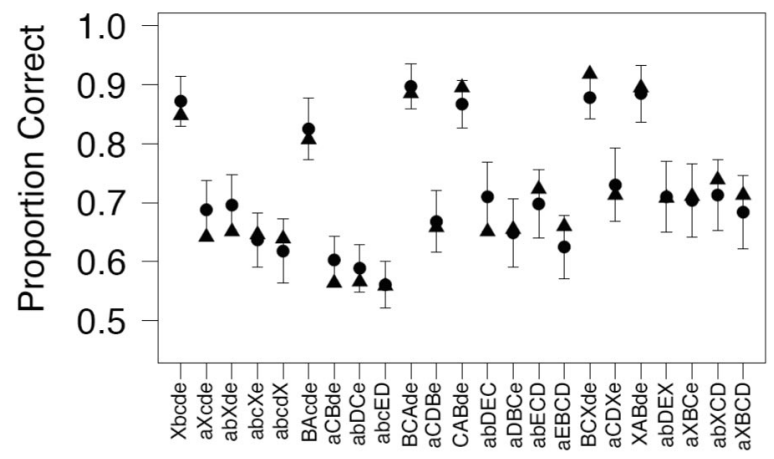

Figure 5. The figure shows the data and model fits for Experiment 3 (see text for description of the different types of items). The circles represent the data, and the triangles represent the model's fits. The different conditions are represented across the $x$-axis, and the proportion of correct responses is represented on the $y$-axis. Error bars indicate two standard errors of the mean.
Table 5

Results From Experiment 3

\begin{tabular}{lll}
\hline \multicolumn{1}{c}{ Condition } & $M(2$ SEs $)$ & Model \\
\hline Replacement 1 & $.872(.042)$ & .848 \\
Replacement 2 & $.688(.050)$ & .642 \\
Replacement 3 & $.696(.052)$ & .651 \\
Replacement 4 & $.637(.046)$ & .646 \\
Replacement 5 & $.618(.054)$ & .639 \\
Transposition 1 and 2 & $.825(.052)$ & .807 \\
Transposition 2 and 3 & $.603(.040)$ & .564 \\
Transposition 3 and 4 & $.589(.040)$ & .566 \\
Transposition 4 and 5 & $.561(.040)$ & .559 \\
Migration letter 1 to 3 & $.897(.038)$ & .885 \\
Migration letter 2 to 4 & $.668(.052)$ & .658 \\
Migration letter 3 to 1 & $.867(.040)$ & .895 \\
Migration letter 3 to 5 & $.710(.058)$ & .651 \\
Migration letter 4 to 2 & $.649(.058)$ & .655 \\
Migration letter 5 to 2 & $.698(.058)$ & .723 \\
Migration letter 5 to 3 & $.625(.054)$ & .660 \\
Migration control letter 1 to 3 & $.878(.036)$ & .918 \\
Migration control letter 2 to 4 & $.730(.062)$ & .713 \\
Migration control letter 3 to 1 & $.885(.048)$ & .895 \\
Migration control letter 3 to 5 & $.710(.060)$ & .708 \\
Migration control letter 4 to 2 & $.704(.062)$ & .711 \\
Migration control letter 5 to 2 & $.713(.060)$ & .739 \\
Migration control letter 5 to 3 & $.684(.062)$ & .713 \\
\hline
\end{tabular}

\section{Results and Modeling}

The data from this experiment provide a stringent test of the model because there are 37 different conditions and only 7 free parameters. The reason for such a large number of conditions is that, unlike the replacement or transposition conditions used in the previous experiments, in which the two alternatives have the same type of similarity to each other (e.g., ABCDE has the same relationship to $\mathrm{XBCDE}$ as $\mathrm{XBCDE}$ has to $\mathrm{ABCDE}$ ), the alternatives in the present experiment have an asymmetrical relationship (e.g., from $\mathrm{ABCDE}$ to $\mathrm{ABBDE}$, there is a repetition plus a removal of the letter $\mathrm{C}$, while from $\mathrm{ABBDE}$ to $\mathrm{ABCDE}$, there is an addition of a letter $C$ and no repeated letter). As can be seen in Table 6 and Figure 6, performance was very different depending on which of the two alternatives was the target (i.e., when the target had a repeated letter, performance was worse than when the target did not have a repeated letter). This effect cannot be explained by overlap differences alone; instead, we assumed that the two power parameters for the overlap values (see Equation 3) are different for the alternative with repeated letters and for the alternative without repeated letters. The data show that the participants were biased toward choosing the alternative without the repeated letters; hence, the power parameter for the strings without repeated letter is larger than for strings with repeated letters. This might be because a repeated letter is difficult to detect in the brief stimulus presentation and therefore, people tend to choose the alternative without the repeated letter.

The overlap model (the fits represented by triangles in the figure) fits 34 out of 37 data points (the circles) in Figure 6 within two standard errors. The model tended to overestimate performance for the conditions in which both the target and the foil had repeated letters (in particular, adjacent repeated letters) and also the ABADE versus ABCDE condition. Thus, the model provides a reasonable account of this data set. Importantly, this is accom- 
Table 6

Results From Experiment 4

\begin{tabular}{|c|c|c|c|c|}
\hline \multirow[b]{2}{*}{ Type of Item } & \multicolumn{2}{|c|}{ Condition } & \multirow[b]{2}{*}{$M(2 S E \mathrm{~s})$} & \multirow[b]{2}{*}{ Model } \\
\hline & Foil & Target & & \\
\hline \multirow[t]{7}{*}{ Repeated letters only in foil } & ABBDE & $\mathrm{ABCDE}$ & $.799(.077)$ & .755 \\
\hline & ABCCE & ABCDE & $.821(.057)$ & .727 \\
\hline & ABCDD & ABCDE & $.794(.082)$ & .743 \\
\hline & ABADE & $\mathrm{ABCDE}$ & $.790(.079)$ & .866 \\
\hline & ABCBE & ABCDE & $.738(.071)$ & .798 \\
\hline & $\mathrm{ABCDC}$ & $\mathrm{ABCDE}$ & $.766(.091)$ & .806 \\
\hline & $\mathrm{ABCDB}$ & $\mathrm{ABCDE}$ & $.820(.066)$ & .848 \\
\hline \multirow[t]{7}{*}{ Repeated letters only in target } & ABCDE & ABBDE & $.691(.083)$ & .699 \\
\hline & ABCDE & ABCCE & $.686(.082)$ & .692 \\
\hline & $\mathrm{ABCDE}$ & ABCDD & $.680(.083)$ & .696 \\
\hline & ABCDE & ABADE & $.683(.070)$ & .632 \\
\hline & $\mathrm{ABCDE}$ & ABCBE & $.692(.074)$ & .674 \\
\hline & $\mathrm{ABCDE}$ & $\mathrm{ABCDC}$ & $.653(.071)$ & .683 \\
\hline & $\mathrm{ABCDE}$ & $\mathrm{ABCDB}$ & $.697(.096)$ & .678 \\
\hline \multirow{12}{*}{ Repeated letters in both } & ABBDE & ADBBE & $.714(.077)$ & .753 \\
\hline & $\mathrm{ABCCE}$ & ACCBE & $.674(.081)$ & .753 \\
\hline & ABCDD & ABDDC & $.746(.072)$ & .799 \\
\hline & ABADE & BADAE & $.812(.087)$ & .872 \\
\hline & $\mathrm{ABCBE}$ & ACBEB & $.705(.093)$ & .676 \\
\hline & $\mathrm{ABCDC}$ & ACBCD & $.727(.065)$ & .686 \\
\hline & ADBBE & ABBDE & $.722(.076)$ & .753 \\
\hline & ACCBE & ABCCE & $.784(.073)$ & .753 \\
\hline & ABDDC & ABCDD & $.751(.075)$ & .800 \\
\hline & BADAE & ABADE & $.887(.059)$ & .835 \\
\hline & ACBEB & ABCBE & $.752(.070)$ & .686 \\
\hline & $\mathrm{ACBCD}$ & $\mathrm{ABCDC}$ & $.728(.090)$ & .676 \\
\hline \multirow[t]{7}{*}{ Transpositions } & ACBDE & $\mathrm{ABCDE}$ & $.642(.071)$ & .590 \\
\hline & ABDCE & ABCDE & $.620(.054)$ & .596 \\
\hline & ABCED & ABCDE & $.695(.073)$ & .592 \\
\hline & CBADE & $\mathrm{ABCDE}$ & $.865(.063)$ & .954 \\
\hline & ADCBE & $\mathrm{ABCDE}$ & $.708(.082)$ & .743 \\
\hline & ABEDC & $\mathrm{ABCDE}$ & $.759(.072)$ & .790 \\
\hline & AECDB & $\mathrm{ABCDE}$ & $.806(.073)$ & .862 \\
\hline \multirow[t]{4}{*}{ Replacements } & AXCDE & $\mathrm{ABCDE}$ & $.784(.077)$ & .728 \\
\hline & ABXDE & ABCDE & $.783(.057)$ & .757 \\
\hline & ABCXE & $\mathrm{ABCDE}$ & $.762(.082)$ & .740 \\
\hline & ABCDX & ABCDE & $.460(.079)$ & .750 \\
\hline
\end{tabular}

plished with parameter values similar to those in the previous experiments (e.g., the $s$ parameter for Position 1 is about half the size [.778] of those for Positions 2-5, which are similar to each other [about 1.5]).

\section{Experiment 5: Subset/Superset Stimuli}

Up to now, the overlap model has provided a reasonable account of the data across a wide range of conditions (replacement of letters, transposition of letters, migration of letters, and lexical status) in which the target stimulus and the foil have the same letter length. In Experiment 5 (see Appendix A), we tested whether the overlap model could deal with the orthographic similarity of items of different length. There is evidence that items of different length can compete with each other (e.g., thirty can compete with thirsty; e.g., Bowers, Davis, \& Hanley, 2005; De Moor \& Brysbaert, 2000; Perea, Acha, \& Fraga, 2008; Perea \& Carreiras, 1998). Van Assche and Grainger (2006) recently found that inserting one or two unrelated letters in a target word, hence creating a superset, generates strong priming effects in the masked priming paradigm (i.e., the prime apgricfot facilitates the processing of the word apricot). We used stimuli of this kind along with conditions employed in previous experiments to help test the model. The critical conditions of particular interest are those in which we add one letter to either the foil or the target. In half of the trials with items of different length, the target was the six-letter item (target: AXBCDE; foil: $\mathrm{ABCDE})$, whereas in the other half the target was the five-letter item (target: ABCDE; foil: AXBCDE).

In sum, for a given nonword, the similar items could be a transposed-letter item, a single replacement item, or an item with an added or deleted letter.

\section{Results and Modeling}

To fit the overlap model to this experiment, we assumed that the five- and six-letter strings spanned the same space, as shown in Figure 7. The top panel represents the overlap (the shaded areas) across the different positions for five-letter test strings (ABCDE) compared with the six-letter test string (ABCXDE). The bottom panel shows the string $\mathrm{ABCXDE}$ overlapping with the five-letter test string (ABCDE).

The model was slightly modified to implement the different letter positions by making the letter strings span the same range. In other words, the boundaries at the two ends of the letter strings were aligned, and the spacing of the boundaries was wider for the shorter letter string relative to the longer string (as shown in Figure 7). When the two alternatives were different only by an inserted letter, the two conditions were different and required different fits depending on whether the target or the foil had the inserted letter. This is because the overlap of the flashed target $\mathrm{ABCDE}$ with the alternative $\mathrm{ABXCDE}$ has different overlap from the flashed target $\mathrm{ABXCDE}$ with the alternative $\mathrm{ABCDE}$

The fits of the model to the data were performed as in the previous experiments (see Figure 8 and Table 7). The model accounts for the replacement and transposition conditions reason-

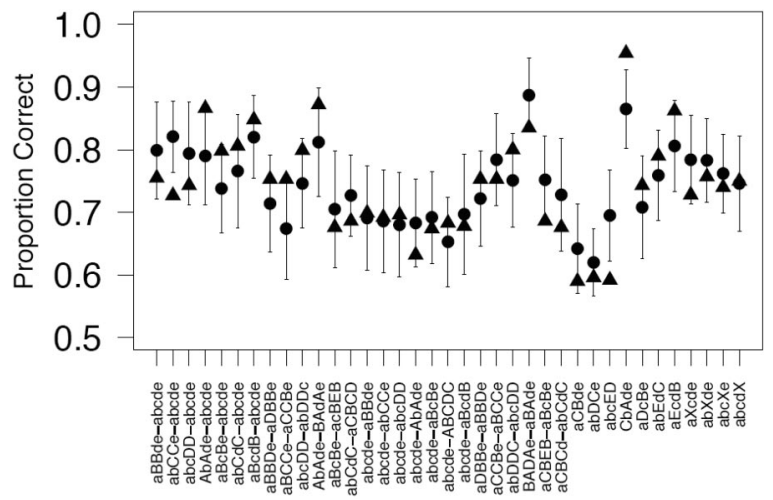

Figure 6. The figure shows the data and model fits for Experiment 4 . The circles represent the data, and the triangles represent the model's fits. The different conditions are represented across the $x$-axis, and the proportion of correct responses is represented on the $y$-axis. Error bars indicate two standard errors of the mean. 

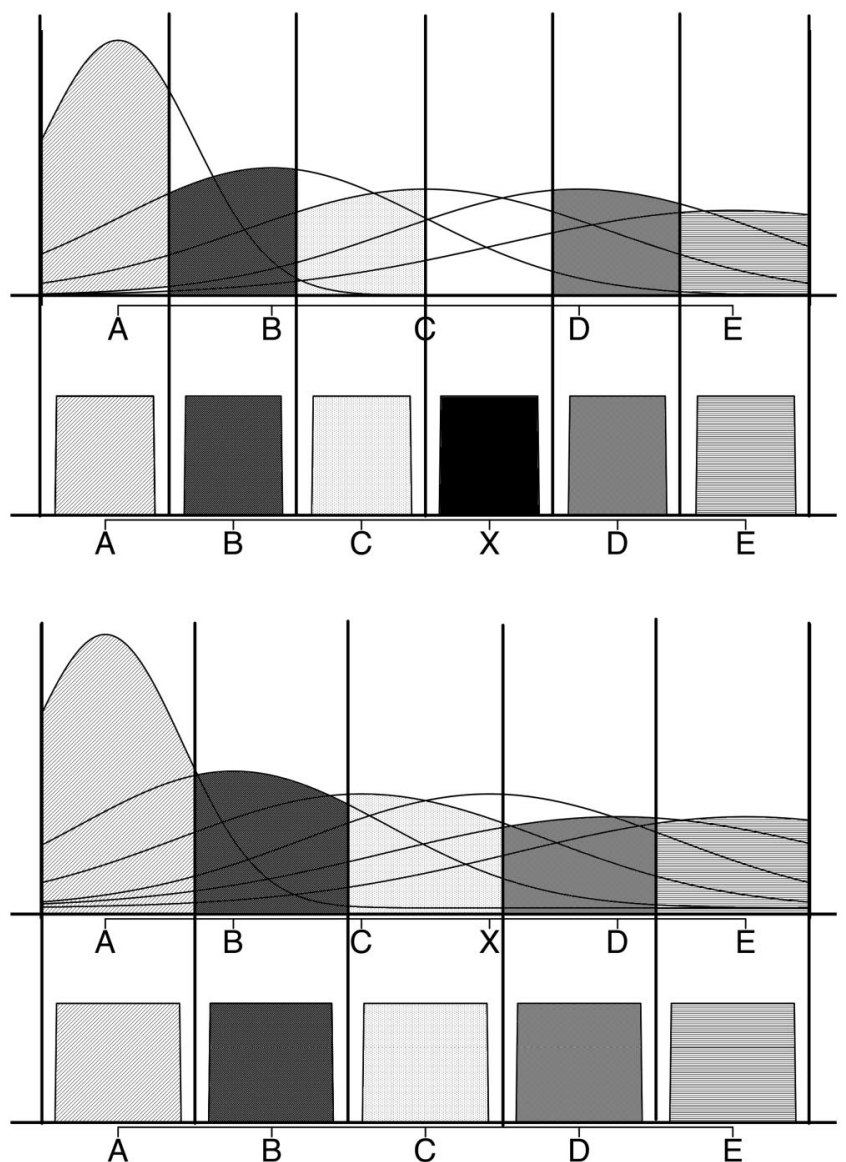

Figure 7. The figure shows a representation of the encoding of letter position with mismatching number of letters. In the top panel, the shaded areas represent the five-letter string $\mathrm{ABCDE}$ overlapping with the six-letter test string ABCXDE; in the bottom panel, the shaded areas represent the overlap between the six-letter string $\mathrm{ABCXDE}$ and the five-letter test string $\mathrm{ABCDE}$.

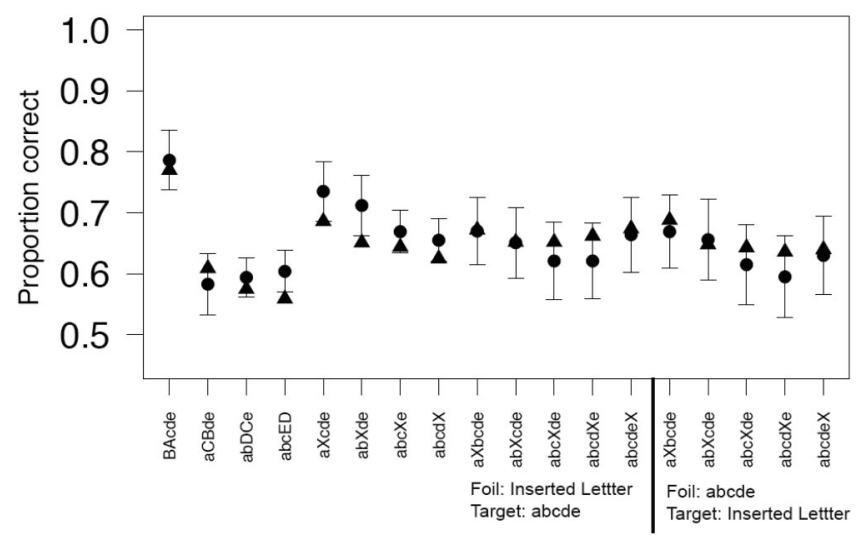

Figure 8. The figure shows the data and model fits for Experiment 5. The circles represent the data, and the triangles represent the model's fits. The different conditions are represented across the $x$-axis, and the proportion of correct responses is represented on the $y$-axis. Note that there are two types of letter insertion trials: The letter insertion could be in the foil or in the target. Error bars indicate two standard errors of the mean.
Table 7

Results From Experiment 5

\begin{tabular}{llc}
\hline \multicolumn{1}{c}{ Condition } & $M(2$ SEs $)$ & Model \\
\hline Transposition 1 and 2 & $.789(.049)$ & .770 \\
Transposition 2 and 3 & $.583(.050)$ & .609 \\
Transposition 3 and 4 & $.594(.032)$ & .575 \\
Transposition 4 and 5 & $.604(.034)$ & .559 \\
Replacement 2 & $.735(.049)$ & .686 \\
Replacement 3 & $.712(.050)$ & .651 \\
Replacement 4 & $.669(.035)$ & .644 \\
Replacement 5 & $.655(.035)$ & .625 \\
Foil insertion between 1 and 2 & $.670(.055)$ & .672 \\
Foil insertion between 2 and 3 & $.651(.058)$ & .652 \\
Foil insertion between 3 and 4 & $.621(.064)$ & .652 \\
Foil insertion between 4 and 5 & $.621(.062)$ & .662 \\
Foil insertion after 5 & $.664(.061)$ & .674 \\
Target insertion between 1 and 2 & $.669(.060)$ & .688 \\
Target insertion between 2 and 3 & $.656(.066)$ & .648 \\
Target insertion between 3 and 4 & $.615(.065)$ & .643 \\
Target insertion between 4 and 5 & $.595(.067)$ & .636 \\
Target insertion after 5 & $.630(.064)$ & .640 \\
\hline
\end{tabular}

ably well. It underestimates performance in the transposition of the fourth and fifth letters and also in the single letter replacement conditions. Nonetheless, the model successfully captures the most important aspects of performance in the letter-insertion trials, with all fits (triangles in Figure 8) for these conditions within two standard errors of the empirical values (circles in Figure 8). As in previous experiments, the parameters of the model behaved in a predictable way (i.e., the $s$ parameter monotonically increased as a function of letter position from about .6 for $s_{1}$ to an average of 1.5 for $s_{2}-s_{5}$ ). In sum, the overlap model provides a good account of the effects of similarity between two strings of different length by using parameter values very similar to those obtained in previous experiments (see Table 3 ).

\section{General Discussion}

The present article has shown how the overlap model can accommodate a variety of effects from experiments that manipulate letter transpositions, letter replacements, letter migrations, letter repetitions, and letter additions/deletions across five perceptual identification experiments. In each experiment, a letter string was presented briefly, it was then masked, and then two test alternatives were presented: One was the target string, and the other was a foil implementing the manipulation of interest. The model does that by implementing minimal assumptions, which are shared by models of object location (e.g., the CODE model, Logan, 1996).

The data from the experiments can be summarized as follows: (a) Letter transpositions produced lower accuracy values than their orthographic control conditions; (b) single replacements produced higher accuracy than transpositions; (c) double replacements produced better performance than single replacement and transposedletters strings; (d) when the test strings were a word and a nonword, there was a bias to choose the word; (e) repetition of letters exhibited a bias-when the target in the forced-choice task included an adjacent repeated letter, participants chose the foil (with no repeated letters) in a higher proportion of the trials than in other conditions; and (f) when the length of the string changed with an 
insertion of a letter relative to the other test alternative, participants appeared to base their response on string similarity, consistent with the overlap model and with the data from other manipulations.

The effects of each of these conditions, namely, letter transposition, single letter replacement, double letter replacement, letter migration, letter insertion, and letter repetition, interacted with position of the manipulation in letter string. Specifically, any manipulation in which the first letter in a string was altered produced higher accuracy than manipulations that involved interior letters; in contrast, the effect of manipulating the final letter did not differ from those in which interior letters were manipulated. ${ }^{2}$ The effects of the manipulations on accuracy were modulated not only by position within the letter string but also by the lexical status of the strings: There was better performance with word targets than with nonword targets.

\section{The Overlap Model}

We have used Ratcliff's (1981) theory of order relations to account for the encoding of letter positions. This account is based on the assumption that the representation of a letter is distributed across ordinal positions in the letter string. The similarity between two strings is the degree of overlap between the letters of the same identity, and the overlap is transformed to accuracy using a power function.

Most of the values predicted by the model were within two standard errors of the data. In most experiments, more than 20 conditions that included many different types of manipulations of a string of letters were fitted with six or seven free parameters. Furthermore, this was accomplished with a high degree of consistency in the parameter values (especially the standard deviations parameter $s$ of the overlap) across the experiments and with minimal additional assumptions for the different types of trials. Later in the General Discussion, we show how we can take advantage of the parameter consistency to reduce the number of

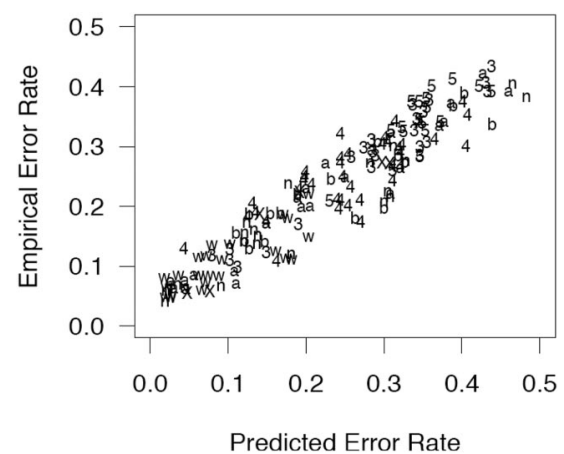

Figure 9. Plot of the predictions of the overlap model and the empirical error rates across all experiments. The symbols correspond to the different types of experiments in this article. $\mathrm{a}=$ Experiment 1a (nonword target and foils); $b=$ Experiment $1 \mathrm{~b}$ (nonword targets and foils with no manipulations of the first letter); $\mathrm{w}=$ Experiment 2 (word targets and nonword foils); $\mathrm{n}=$ Experiment 2 (nonword targets and word foils); $\mathrm{x}=$ Experiment 2 (word targets and word foils); $3=$ Experiment 3 (nonword targets and foils with letter migration); $4=$ Experiment 4 (nonword targets and foils with double letters); $5=$ Experiment 5 (nonword targets and foils with letter insertion). parameters related to position uncertainty from five to two. There were a total of 171 conditions in the experiments reported in this paper; the correlation between the empirical accuracies for these 171 conditions and the predictions of the overlap model was $r=$ $.942, t(169)=36.52, p<.001$. Figure 9 presents a plot of the empirical data and the model's predictions; as can be seen, the model does not exhibit any systematic departures from the empirical data.

Figure 10 shows a plot of the overlap between the targets and the foils for each condition and the predicted error rate. There is a curvilinear relationship that is particularly clear in the higher accuracy conditions. This means that changes in the overlap values produce smaller effects in the predicted accuracy rates in easier conditions than in difficult conditions. Note that in Experiments 2 and 4 , the data fall on points that form more than one line per experiment. They represent those conditions in which two scaling parameters (one for each alternative) were used, as in the wordnonword condition (w points in the figure), the word-word condition (x points in the figure), and in the conditions with repeated letters in the target but not in the foil (4 points in the figure). The $a$ parameter scales the differences in overlap values and differentially scales the match between the target and each of the two alternatives.

Finally, we should note that the $s$ parameter in the overlap model has a straightforward interpretation in terms of developmental studies in letter position coding. Prior research has found that transposed-letter effects are greater for beginning readers than for adult readers (Acha \& Perea, 2008b; Castles, Davis, \& Forster, 2003; Perea \& Estévez, 2008). As pointed out by Castles et al. (2003), "the immature word recognition system tolerates a degree of error in letter position if letter identity requirements are fulfilled" (p. 353). In the overlap model, the noisy locations of objects (e.g., letters) in beginning readers would be reflected as larger $s$ values. Note that in an extreme case, an impairment of the processes underlying letter position coding may lead to letter position dyslexia (see Friedmann \& Gvion, 2001, 2005).

\section{Implications for Modeling Word Recognition}

Three other models of letter position encoding have been proposed in the past decade: the open-bigram model (Grainger \& van Heuven, 2003), the SERIOL model (Whitney, 2001, in press), and the SOLAR model (Davis, 1999, 2002). In this section, we briefly summarize them and show results from simulations of these three models along with the overlap model's fits to the empirical data presented in this article. It is critical to point out that there are two reasons why these predictions should not be used to rule out those models: (a) Only the letter coding component of such models is

\footnotetext{
${ }^{2}$ As Whitney (2001) noted, previous research in which there was a final-letter advantage involved presentation durations of $75 \mathrm{~ms}$ or more, whereas those experiments in which a final-letter advantage did not occur involved presentation durations of $50 \mathrm{~ms}$ or less; in the present experiments, the stimulus was presented for $60 \mathrm{~ms}$, and the observed pattern is consistent with Whitney's review. Ratcliff (1981) found final-letter advantage in some conditions in his perceptual matching experiments. The overlap model accommodated the final-letter assumption with a smaller standard deviation for the final-letter position relative to earlier letter positions.
} 
tested, and (b) the simulations produce results based on generic parameter values (not fits).

Grainger and van Heuven's (2003) open-bigram model is based on the assumption that the relative position of a letter is coded on the basis of its local context, that is, coded with the context of letters that co-occur within the string (up to a limit of two intervening letters). This local context corresponds to a set of openbigram units. For instance, the open bigrams for the word judge would be $j u, j d, j g, u d, u g$, ue, $d g$, de, and $g e$. Under Grainger and van Heuven's original formulation, je would not be an activated open bigram because its distance is beyond the limit of two intervening letters. ${ }^{3}$

The architecture of the Grainger and van Heuven (2003) model is shown in Figure 11. The input for the model is the visual stimulus, processed by the alphabetic array, which is a bank of detectors that processes all the characters in parallel and provides an accurate retinotopic map of the string. The information in the alphabetic array is fed on to the relative order map, which is composed of units that code whether ordered pairs of letters are present in the alphabetic array. Grainger and van Heuven used this model to compute similarity between primes and targets to account for masked priming results with transposed-letter items.

The SERIOL (sequential encoding regulated by inputs to oscillation within letter units; Whitney, 2001, in press; see also Whitney \& Berndt, 1999; Whitney \& Lavidor, 2005) model was designed to explain the process of reading strings of letters, from graphic feature detection to word identification. The model has five implemented layers: edge, feature, letter, bigram, and word. This model uses a letter-tagging coding scheme, in which each letter is marked for the ordinal position in which it occurs within a letter string. For instance, the word slat would be represented by S-1, L-2, A-3, T-4. This letter-tagging scheme is also accompanied by the activation of bigram nodes - ordered pairs of letters-so that the word slat would be represented by the following bigrams: $s l$, la, at, sa, st, and lt (cf. Grainger \& van Heuven's, 2003, model). For example, slat shares three bigram nodes with the transposed-

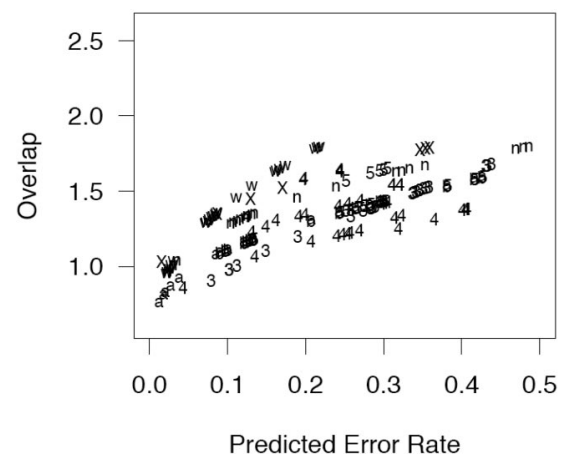

Figure 10. Plot of the overlap value and the predicted error rates for all the experiments. The symbols correspond to the different types of experiments in this article. $\mathrm{a}=$ Experiment $1 \mathrm{a}$ (nonword target and foils); $\mathrm{b}=$ Experiment $1 \mathrm{~b}$ (nonword targets and foils with no manipulations of the first letter); $\mathrm{w}=$ Experiment 2 (word targets and nonword foils); $\mathrm{n}=$ Experiment 2 (nonword targets and word foils); $\mathrm{x}=$ Experiment 2 (word targets and word foils); 3 = Experiment 3 (nonword targets and foils with letter migration); 4 = Experiment 4 (nonword targets and foils with double letters); $5=$ Experiment 5 (nonword targets and foils with letter insertion).

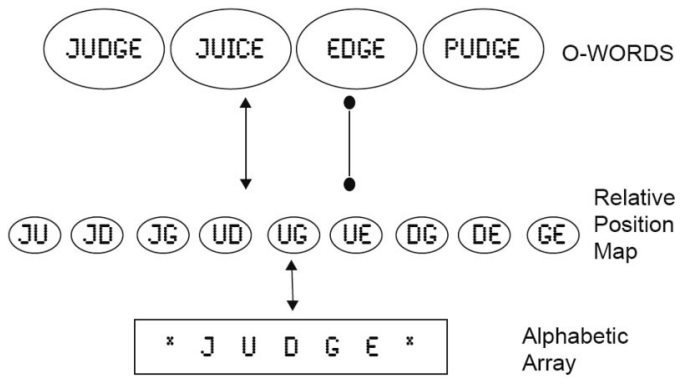

Figure 11. Architecture of the open-bigram model. The alphabetic array is a bank of letter detectors that processes the visual stimulus. The information in the alphabetic array is decomposed in the relative position map, which in turn activates the whole-word representations in the O-word layer (adapted from Figure 1 in Grainger \& van Heuven, 2003).

letter neighbor salt ( $s a, l t, s l)$, which is the same number it shares with the one-letter-different neighbor scat ( $s a, a t, s t)$. Thus, salt would be equally similar to and equally confusable with both slat and scat.

More specifically, in the SERIOL model, during the process of visual word recognition, each letter node undergoes synchronous excitatory subthreshold oscillations resulting in a sequential firing in left-to-right sequential manner (in Western languages). In the oscillatory cycle, only the letter node receiving the highest level of input can exceed threshold and fire (e.g., the letter $t$ in the word trial), and as excitation increases over time, the letter node receiving the next highest level of input can fire (i.e., $r$ ), and so on. It is important to note that the temporal encoding of letter nodes also activates bigram nodes and that the activity across bigram nodes is used to activate lexical units. The amount of activation of each bigram node depends on its constituent letter activations, although it is also influenced by the firing delay between those letter nodes when neither letter node is highly activated (i.e., the firing delay makes the open bigram $t r$ more highly activated than the open bigram $t a$ in the word trial). Thus, the bigrams that encode the first/second and first/last letters of a string are the most highly activated, and those encoding the second/third and second/last letters are the next most highly activated, and so on (see Whitney \& Lavidor, 2005). As a result, two words will be the most perceptually similar when they share the most highly active bigrams, and this would be independent of string length. This predicts that hose may activate the lexical entry of house (i.e., the effects of addition/deletion neighbors; see Experiment 5).

Both the open-bigram model and the SERIOL model require an input that contains information about letter position before they can extract the bigrams. More specifically, these models use this input (in which the letter positions are correctly encoded) to produce a noisy encoding of position. The SOLAR model, on the other hand, uses a spatial coding scheme (see Figure 12 for a graphical representation) in which the order of letters is coded by the relative activity of a set of letter nodes. In this way, the transposed-letters words salt and slat

\footnotetext{
${ }^{3}$ In our experiments, we have shown that letter transpositions that are even three letters distant show larger similarity than the control conditions; however, the Grainger and van Heuven (2003) model could readily be extended to include bigrams separated by more than two letters.
} 


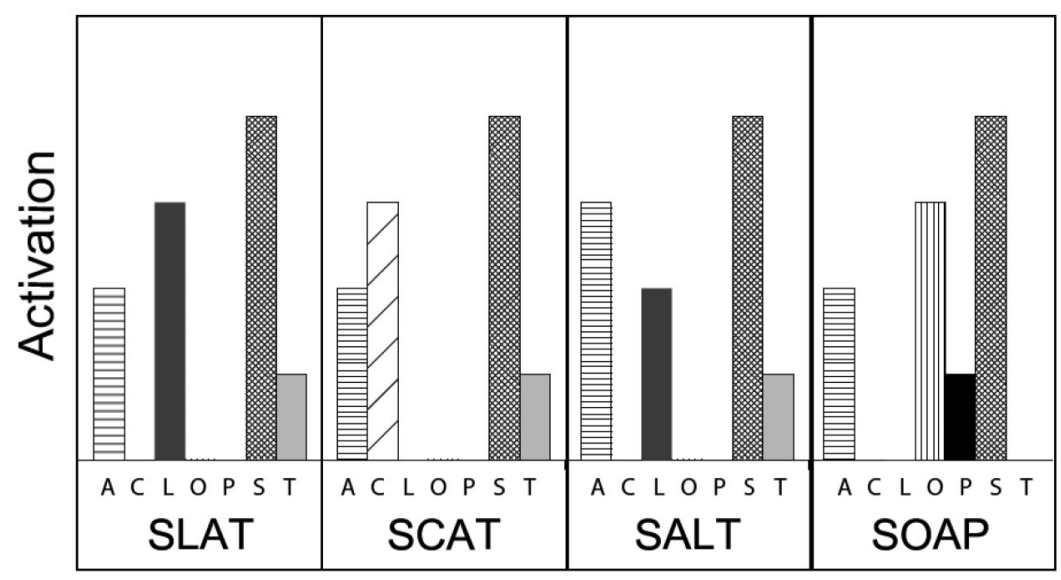

Figure 12. The different panels in the figure show the sequential coding in the SOLAR model for the words SLAT, SCAT, SALT and SOAP (adapted from Figure 1 in Davis \& Bowers, 2004). Within each panel, the $x$-axis shows an unordered set of letters, and the $y$-axis shows the activation for each of these letters.

share the same set of letter nodes, but they produce different spatial patterns. The SOLAR model also assumes the presence of a left-toright serial input (in Western languages), such that the letters are processed sequentially. Because serial position is coded by relative activities rather than via position-specific codes, and because of the way the network computes bottom-up input, salt and slat are more similar and, hence, more confusable than slat and scat. Thus, the SOLAR model can readily explain some transposed-letters similarity effects. The coding scheme of the SOLAR model is only the front end of the model; indeed, the model can account for a number of phenomena in the literature (e.g., lexical status, frequency, orthographic neighborhood, masked priming, and pseudohomophone effects).

There is one basic difference between the overlap model and the open-bigram, SERIOL, and SOLAR models. These last three models include an intermediate stage that requires (and uses) accurate information about letter position to extract bigrams to represent order. This order representation is then used to produce a noisy representation of position. One can ask why the system cannot access this accurate information about position. In contrast, in the overlap model a perfectly accurate position encoding is not available during matching a test to a study string (though accurate position information might be produced by other processes).

We compared the predictions of the four models (the overlap model, the SERIOL model, the open-bigram model, and the SOLAR model) by using predictions from the parameter values for the overlap model and by using Davis's (2007) MatchCalculator program ${ }^{4}$ for the latter three models. Again, the output of the MatchCalculator program is obtained with generic parameter values, unlike the predictions of the overlap model, which are obtained by fitting the model to the data. The predictions were used to produce correlations between target-foil similarities for each model and between the models and the empirical error rates (averaged from Experiments 1a, 1b, 3, and 5) for the transposed-letter, letter replacement, letter migration, control for letter migration, and letter insertion conditions. For the overlap model, we did not include the scaling parameter $a$, so the comparison among models was solely on the basis of string similarity. The scatterplots between the models' string similarity predictions and the empirical error-rate values are shown in Figure 13. The correlations between the model similarities and the data are .588 for the open-bigram model, ${ }^{5} .655$ for the SOLAR model, ${ }^{6} .850$ for the SERIOL model, and .927 for the overlap model. This very high correlation found between the data and the overlap model indicates that our model provides an excellent description of how string similarity affects performance in the forced-choice task. Of course, comparing these correlations should be done with caution, and they are presented here not with the intention of falsifying the other models but to show that the overlap model can account for the data at least as well as the letter coding component of the other models.

Interestingly, we should also note that a nonimplemented neural model of letter position coding has been proposed recently by Dehaene, Cohen, Sigman, and Vinckier (2005). This model as-

\footnotetext{
${ }^{4}$ This program can be downloaded from Colin Davis's Web site at http://www.pc.rhul.ac.uk/staff/c.davis/Utilities/MatchCalc/index.htm.

${ }^{5}$ In a recent article, Grainger, Granier, Farioli, Van Assche, and van Heuven (2006) indicated that open bigrams would be weighted according to the amount of distance between the component letters in the input string. In this case, the predictions of this "overlap open-bigram" model would be closer to those provided by the SERIOL model.

${ }^{6}$ It is possible that some tweaking of the parameters of the SOLAR model would produce a better correlation value. One option, suggested by Colin Davis, would be to compute the correlation after a constant of .3 had been subtracted from the match value for each of the 16 conditions in which there was a mismatch between the initial letters of the target and foil stimuli (e.g., the match between $\mathrm{ABCDE}$ and $\mathrm{BACDE}$ would change from .89 to .59 , whereas the match between $\mathrm{ABCDE}$ and $\mathrm{ACBDE}$ would remain unchanged at .89). The subtraction of this constant would be intended to reflect the decreased likelihood of participants choosing a foil with a mismatch in the initial letter (whether due to phonological factors or purely orthographic factors based on the reduced position uncertainty associated with this position). This modification had the effect of increasing the correlation coefficient up to $r=.90$.
} 

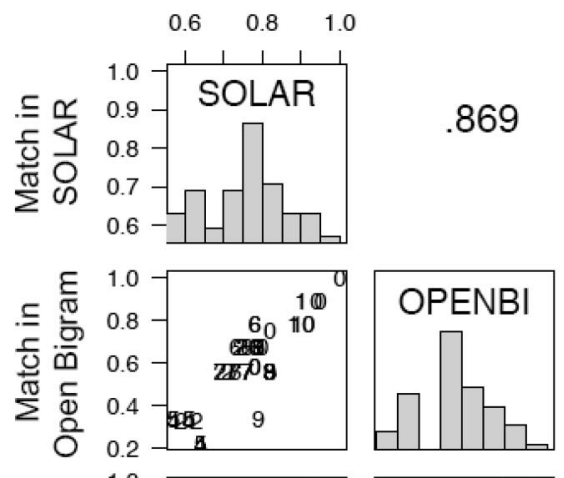

.674

.740

.655
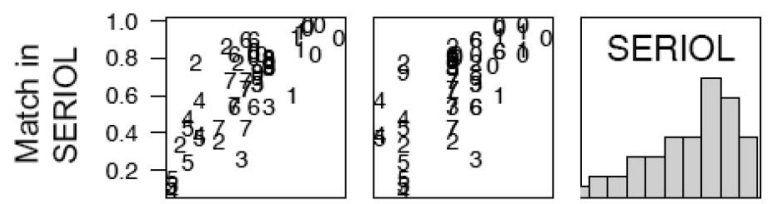

.596

.588
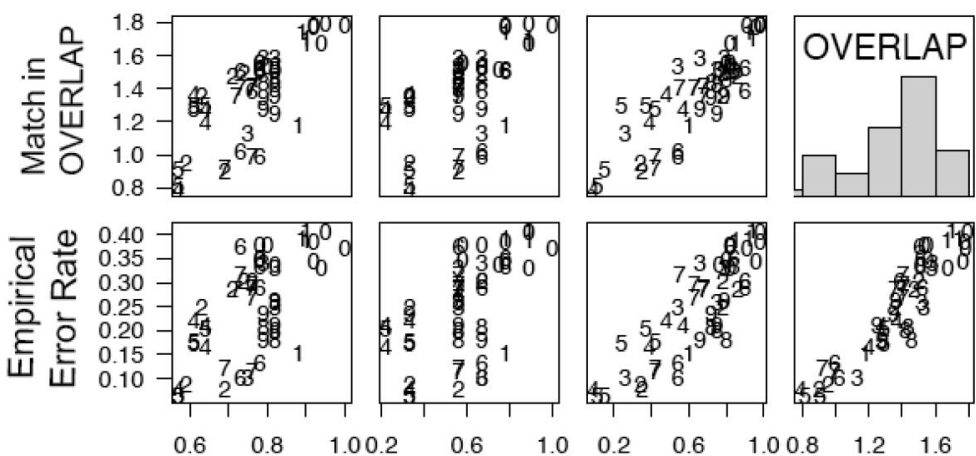

$0.6 \quad 0.8$

Match in

0.20 .6

$0.8 \quad 1.2 \quad 1.6$

.860

.850

SOLAR

Open Bigram

Match in

Match in

OVERLAP

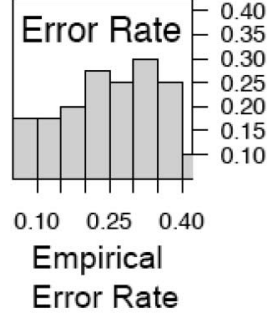

Figure 13. The bottom left panels show scatterplots of the similarity values for the four models (overlap model, SERIOL model, open-bigram model, and SOLAR model) and the error-rate data. The points are represented by numbers that correspond to the type of item: $1=$ adjacent transpositions; $2=$ nonadjacent transpositions; $3=$ single replacements; $4=$ adjacent replacements; $5=$ nonadjacent replacements; $6=$ letter migration; $7=$ migration + insertion; $8=$ double letters; $9=$ nonadjacent letter repetition; $0=$ letter insertion. The diagonal panels show histograms of values, and the top right panels show the correlations.

sumes the existence of a noisy letter-detection system at the level of the so-called visual word form area, an assumption that is compatible with the overlap model, and furthermore, it provides biological plausibility to the idea of noisy letter position coding in terms of neural activity.

Finally, the generalization of the front end of a visual wordrecognition model to the context of normal reading is challenging for all current coding schemes, in particular the role of parafoveal information. In turn, a highly successful model of normal reading such as the EZ reader model (Reichle, Pollatsek, Fisher, \& Rayner, 1998) does not have a lexical/orthographic module, and hence, it makes no specific predictions concerning letter position coding (see Johnson et al., 2007). Further research is necessary to provide a link between the input coding scheme in models of visual word recognition and the when/where processes in models of eyemovement control. Consistent with the assumptions of the overlap model, letter position coding in normal reading is less accurate in the measures that reflect early stages (e.g., first fixation durations in parafoveal priming experiments), while it becomes more precise in later measures of eye movements (see Johnson, 2007).

\section{Reducing Number of Parameters in the Overlap Model}

As can be seen in Table 3, the values of standard deviation parameters are quite similar across experiments. This allows us to reduce the number of parameters by fitting the standard deviation for each position with a simple exponential growth to asymptote function over letter position:

$$
s_{i}=d(1-\exp [-(i-.5) / r]) .
$$

The value of the $s$ parameter rises across letter positions $(i)$ with rate $r$ until it reaches an asymptotic value $d$. By using this function, we are able to reduce the number of free parameters for $s$ from five to two with relatively little loss of accuracy of the fits; these two parameters, along with one or two scaling parameters ( $a$ in Equation 2 or $a$ and $b$ in Equation 3) yield three or four free parameters, which are able to account for between 16 and 36 degrees of freedom per experiment in the data. Figure 14 shows the best fitting exponential functions (the lines) and the $s$ parameters reported in Table 3. Each of the panels corresponds to a different data set: The A points (in the top left panel) correspond to the $s_{1}$ to $s_{5}$ parameters in Experiment 1a; the B's 


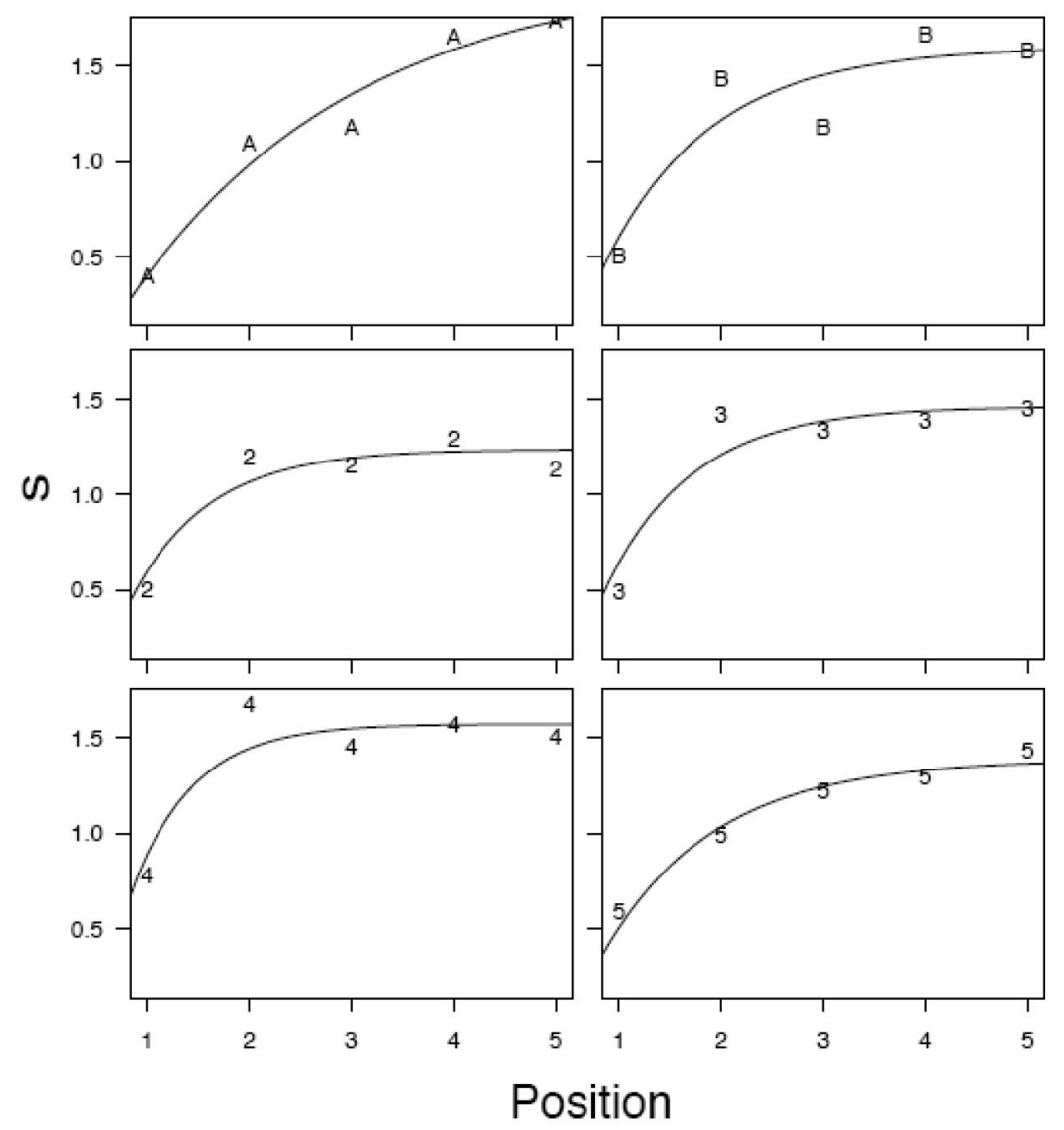

Figure 14. The different panels show the parameters $s_{1}$ to $s_{5}$ for each of the data sets $\mathrm{A}=$ Experiment $1 \mathrm{a} ; \mathrm{B}=$ Experiment 1b;2 $=$ Experiment 2; $3=$ Experiment 3; $4=$ Experiment 4; $5=$ Experiment 5 . The lines show the best fitting exponential approach to a limit function.

correspond to Experiment 1b; and the 2's, 3's, 4's, and 5's correspond to Experiments 2, 3, 4, and 5, respectively. As can be seen, the exponential growth to an asymptote provides an excellent description of the $s$ parameter behavior across position.

For each data set, after the exponential function was fit to the original parameters (the ones reported in Table 3), a new set of $s$ values was generated with Equation 4 . Then, the original scaling parameters (the $a$ and $b$ in Equations 2 and 3) were used to generate predictions.

The predictions from the three or four parameter (asymptote, rate, and one or two scaling exponents) model provide an excellent account of the experimental data. Figure 15 presents a plot of the obtained error rates and the error rates predicted by the simplified model, and it is very similar to Figure 9, which used the original standard deviation parameters. The correlation between the observed and the predicted error-rate values is $r=.923, t(169)=$ $31.07, p<.001$, which is only marginally smaller than the one with the original parameters $(r=.942)$.

To reduce the number of parameters even more, we obtained the average values for the asymptote $d$ and the rate $r$ across the six data sets (average $r=1.094$, and average $d=1.544$ ) and generated overlap values (Equation 1) for the 81 conditions (Experiments 1a, $1 \mathrm{~b}, 3$, and 5) for which two exponents were not needed (Equation 3 ). The overlap values generated by this two-parameter model have a correlation with experimental accuracy values of $r=.915$, $t(79)=20.187, p<.001$ (see Figure 15).

To reiterate, these same conditions were used to obtain the correlations between the data and the open-bigram, SOLAR, and SERIOL models. The correlations between the error-rate data and the models were .616 for the open-bigram model, .703 for the SOLAR model, and .895 for the SERIOL model. Thus, this highly simplified version of the overlap model (with parameter values obtained by averaging across experiments) provides a fit to the data that is as good as or better than the open-bigram, SOLAR, and SERIOL models described above. The correlation of overlap with experimental data for the two-parameter model puts the comparison of the overlap model on a closer footing with the comparisons with the SERIOL, open-bigram, and SOLAR models because the models are not individually fit to experimental data.

To provide one additional comparison in which none of the models had been fit to data, we compared the similarity match values from the overlap, SERIOL, open-bigram, and SOLAR models with data from Experiment 3 in Ratcliff (1987). This experiment was designed to distinguish between conditions in which absolute position is similar in study and test strings and conditions in which relative position is similar in study and test strings. For example, for a study string $\mathrm{ABCDE}$, the test string BCDEA has no letter in correct absolute position but has four letters in correct relative position. None of the 


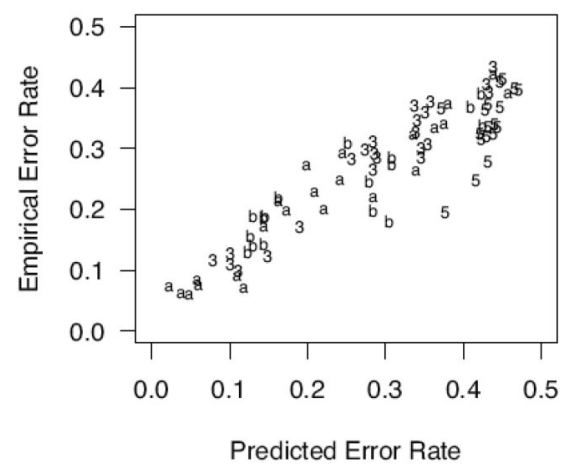

Figure 15. The figure shows plots of the similarity values for the two-parameter model (a rate $r$ of 1.105 and an asymptote $d$ of 1.617 for the exponential function in Equation 4). $\mathrm{a}=$ Experiment $1 \mathrm{a} ; \mathrm{b}=$ Experiment $1 \mathrm{~b} ; 3=$ Experiment $3 ; 5=$ Experiment 5 . four models were fit to the data, and the generic parameter values (including the two exponential function parameters from the overlap model) were used to generate similarity values. The error-rate data and models' predictions are shown in Table 8, and the simplified (two-parameter) overlap model provides a better account of the data ( $r=.850$ between overlap and proportion of correct) than the SOLAR $(r=.522$; but see footnote 6$)$, SERIOL ( $r=.603)$, and open-bigram $(r=.545)$ models. Thus, it is clear that the overlap model provides a highly plausible mechanism for the early stages of letter position coding.

Finally, Appendix B also provides some overlap values for comparison with masked priming effects. These additional analyses show that the positional encoding mechanisms described in this article are compatible with the masked priming effects that have been reported in a segment of the literature on letter position coding.

In sum, developing theories that can be applied across experimental domains is an important step toward the goal of developing general theoretical principles of cognition. The overlap model discussed in this article is based upon principles similar to modern attention theories like Logan's (1996) CODE theory and classic theories of order information in memory like Estes's (1975). We

Table 8

Predictions of Different Models and Data From Archival Data (Ratcliff, 1987, Experiment 3)

\begin{tabular}{|c|c|c|c|c|c|c|}
\hline & & \multicolumn{4}{|c|}{ Model } & \multirow{2}{*}{$\begin{array}{c}\text { Error rate in Ratcliff's } \\
\text { (1987) Experiment } 3\end{array}$} \\
\hline \multicolumn{2}{|c|}{ Alternatives } & SOLAR & Open bigram & SERIOL & Overlap & \\
\hline $\mathrm{ABCDE}$ & ABCED & .68 & .78 & .70 & 1.61 & .570 \\
\hline $\mathrm{ABCDE}$ & ABDCE & .87 & .89 & .82 & 1.60 & .391 \\
\hline ABCDE & ABDEC & .62 & .67 & .54 & 1.46 & .238 \\
\hline $\mathrm{ABCDE}$ & ABECD & .62 & .67 & .54 & 1.45 & .237 \\
\hline $\mathrm{ABCDE}$ & ABEDC & .61 & .56 & .39 & 1.40 & .254 \\
\hline ABCDE & ACBDE & .87 & .89 & .82 & 1.55 & .330 \\
\hline ABCDE & ACBED & .55 & .67 & .53 & 1.46 & .224 \\
\hline $\mathrm{ABCDE}$ & ACDBE & .74 & .78 & .67 & 1.41 & .268 \\
\hline ABCDE & ACDEB & .67 & .56 & .57 & 1.30 & .178 \\
\hline $\mathrm{ABCDE}$ & ACEBD & .46 & .56 & .47 & 1.26 & .164 \\
\hline ABCDE & ACEDB & .56 & .44 & .43 & 1.24 & .157 \\
\hline $\mathrm{ABCDE}$ & ADBCE & .74 & .78 & .66 & 1.36 & .263 \\
\hline $\mathrm{ABCDE}$ & ADBEC & .46 & .56 & .47 & 1.23 & .162 \\
\hline ABCDE & ADCBE & .68 & .67 & .51 & 1.32 & .244 \\
\hline $\mathrm{ABCDE}$ & ADCEB & .53 & .44 & .43 & 1.21 & .173 \\
\hline $\mathrm{ABCDE}$ & ADEBC & .38 & .44 & .43 & 1.03 & .139 \\
\hline ABCDE & ADECB & .38 & .33 & .30 & 1.05 & .137 \\
\hline $\mathrm{ABCDE}$ & AEBCD & .67 & .56 & .57 & 1.25 & .162 \\
\hline ABCDE & AEBDC & .56 & .44 & .43 & 1.20 & .174 \\
\hline ABCDE & AECDB & .60 & .33 & .33 & 1.19 & .210 \\
\hline ABCDE & AECBD & .53 & .44 & .43 & 1.21 & .159 \\
\hline ABCDE & AEDBC & .38 & .33 & .30 & 1.06 & .157 \\
\hline ABCDE & AEDCB & .47 & .22 & .16 & 1.09 & .149 \\
\hline $\mathrm{ABCDE}$ & AXCDE & .80 & .56 & .66 & 1.38 & .250 \\
\hline ABCDE & ABXDE & .80 & .56 & .59 & 1.43 & .218 \\
\hline $\mathrm{ABCDE}$ & ABCXE & .80 & .56 & .66 & 1.44 & .333 \\
\hline $\mathrm{ABCDE}$ & ABCDX & .80 & .67 & .66 & 1.45 & .380 \\
\hline ABCDE & BACDE & .68 & .78 & .69 & 1.20 & .113 \\
\hline $\mathrm{ABCDE}$ & CBADE & .61 & .56 & .38 & 0.94 & .090 \\
\hline ABCDE & DBCAE & .60 & .33 & .33 & 0.88 & .090 \\
\hline ABCDE & EBCDA & .60 & .33 & .33 & 0.86 & .092 \\
\hline $\mathrm{ABCDE}$ & XBCDE & .80 & .67 & .66 & 1.09 & .129 \\
\hline ABCDE & CABDE & .62 & .67 & .54 & 0.95 & .100 \\
\hline $\mathrm{ABCDE}$ & BCADE & .62 & .67 & .54 & 1.03 & .105 \\
\hline \multicolumn{7}{|c|}{$\begin{array}{l}\text { Correlation between Ratcliff } \\
\text { (1987) data and model }\end{array}$} \\
\hline predict & & $r=.522$ & $r=.545$ & $r=.603$ & $r=.850$ & \\
\hline
\end{tabular}


hope that the overlap model can serve as a common organizing structure between the fields of attention, memory, and word recognition.

\section{References}

Acha, J., \& Perea, M. (2008a). The effect of neighborhood frequency in reading: Evidence with transposed-letter neighbors. Cognition, 108, 290-300.

Acha, J., \& Perea, M. (2008b). The effects of length and transposed-letter similarity in lexical decision: Evidence with beginning, intermediate, and adult readers. British Journal of Psychology, 99, 245-264.

Allport, D. A. (1977). On knowing the meaning of words we are unable to report: The effect of visual masking. In S. Dornic (Ed.), Attention and performance VI (pp. 505-533). Hillsdale, NJ: Erlbaum.

Andrews, S. (1996). Lexical retrieval and selection processes: Effects of transposed-letter confusability. Journal of Memory and Language, 35, $775-800$

Ashby, F. G., Prinzmetal, W., Ivry, R., \& Maddox, W. T. (1996). A formal theory of feature binding in object perception. Psychological Review, 103, 165-192.

Bates, D. M., \& Chambers, J. M. (1992). Nonlinear models. In J. M. Chambers \& T. J. Hastie (Eds.), Statistical models in $S$ (pp. 421-453). Pacific Grove, CA: Wadsworth.

Bowers, J. S., Davis, C. J., \& Hanley, D. A. (2005). Automatic semantic activation of embedded words: Is there a "hat" in "that"? Journal of Memory and Language, 52, 131-143.

Bruner, J. S., \& O'Dowd, D. (1958). A note on the informativeness of parts of words. Language and Speech, 1, 98-101.

Carreiras, M., \& Perea, M. (2002). Masked priming effects with syllabic neighbors in the lexical decision task. Journal of Experimental Psychology: Human Perception and Performance, 28, 1228-1242.

Castles, A., Davis, C., \& Forster, K. I. (2003). Word recognition development in children: Insights from masked-priming. In S. Kinoshita \& S. Lupker (Eds.), Masked priming: State of the art (pp. 345-360). Hove, England: Psychology Press.

Chambers, S. M. (1979). Letter and order information in lexical access. Journal of Verbal Learning and Behavior, 18, 225-241.

Christianson, K., Johnson, R. L., \& Rayner, K. (2005). Letter transpositions within and across morphemes. Journal of Experimental Psychology: Learning, Memory, and Cognition, 31, 1327-1339.

Coltheart, M., Rastle, K., Perry, C., Langdon, R., \& Ziegler, J. (2001). DRC: A dual route cascaded model of visual word recognition and reading aloud. Psychological Review, 108, 204-256.

Compton, B. J., \& Logan, G. D. (1993). Evaluating a computational model of perceptual grouping by proximity. Perception \& Psychophysics, 53, 403-421.

Davis, C. J. (1999). The self-organizing lexical acquisition and recognition (SOLAR) model of visual word recognition. Dissertation Abstracts International, 62(01), 594B.

Davis, C. J. (2002). When knowing what is not the same as knowing where. Australian Journal of Psychology, 54, 54.

Davis, C. J. (2007). MatchCalculator [Software]. Available from the author: http://www.pc.rhul.ac.uk/staff/c.davis/Utilities/MatchCalc/ index.htm

Davis, C. J., \& Bowers, J. S. (2004). What do letter migration errors reveal about letter position coding in visual word recognition? Journal of Experimental Psychology: Human Perception and Performance, 30, 923-941.

Davis, C. J., \& Bowers, J. S. (2006). Contrasting five different theories of letter position coding: Evidence from orthographic similarity effects. Journal of Experimental Psychology: Human Perception and Performance, 32, 535-557.

Dehaene, S., Cohen, L., Sigman, M., \& Vinckier, F. (2005). The neural code for written words: A proposal. Trends in Cognitive Sciences, 9, 335-341.

De Moor, W., \& Brysbaert, M. (2000). Neighborhood-frequency effects when primes and targets have different lengths. Psychological Research, $63,159-162$
Estes, W. K. (1975). The locus of inferential and perceptual processes in letter identification. Journal of Experimental Psychology: General, 104, $122-145$.

Estes, W. K., Allmeyer, D. H., \& Reder, S. M. (1976). Serial position functions for letter identification at brief and extended exposure durations. Perception \& Psychophysics, 19, 1-15.

Forster, K. I., \& Davis, C. (1984). Repetition priming and frequency attenuation in lexical access. Journal of Experimental Psychology: Learning, Memory, and Cognition, 10, 680-698.

Forster, K. I., Davis, C., Schoknecht, C., \& Carter, R. (1987). Masked priming with graphemically related forms: Repetition or partial activation? Quarterly Journal of Experimental Psychology: Human Experimental Psychology, 39(A), 211-251.

Friedmann, N., \& Gvion, A. (2001). Letter position dyslexia. Cognitive Neuropsychology, 18, 673-696.

Friedmann, N., \& Gvion, A. (2005). Letter form as a constraint for errors in neglect dyslexia and letter position dyslexia. Behavioral Neurology, $16,145-158$

Gomez, P., Ratcliff, R., \& Perea, M. (2007). A model of the go/no-go task. Journal of Experimental Psychology: General, 136, 389-413.

Grainger, J. (2008). Cracking the orthographic code: An introduction. Language and Cognitive Processes, 23, 1-35.

Grainger, J., Granier, J. P., Farioli, F., Van Assche, E., \& van Heuven, W. (2006). Letter position information and printed word perception: The relative-position priming constraint. Journal of Experimental Psychology: Human Perception and Performance, 32, 865-884.

Grainger, J., \& Jacobs, M. (1996). Orthographic processing in visual word recognition: A multiple read-out model. Psychological Review, 103, 518-565.

Grainger, J., \& van Heuven, W. J. B. (2003). Modeling letter position coding in printed word perception. In P. Bonin (Ed.), Mental lexicon: Some words to talk about words (pp. 1-23). Hauppauge, NY: NOVA Science Publishers.

Guerrera, C., \& Forster, K. (2007). Masked form priming with extreme transposition. Language and Cognitive Processes, 23, 117-142.

Holmes, V. M., \& Ng, E. (1993). Word-specific knowledge, wordrecognition strategies, and spelling ability. Journal of Memory and Language, 32, 230-257.

Jacobs, A. M., Rey, A., Ziegler, J. C., \& Grainger, J. (1998). MROM-p: An interactive activation, multiple readout model of orthographic and phonological processes in visual word recognition. In J. Grainger \& A. Jacobs (Eds.), Localist connectionist approaches to human cognition (pp. 147-188). Mahwah, NJ: Erlbaum.

Johnson, R. L. (2007). The flexibility of letter coding: Nonadjacent letter transposition effects in the parafovea. In R. Van Gompel, M. Fischer, W. Murray, \& R. L. Hill (Eds.), Eye movements: A window on mind and brain (pp. 425-440). Oxford, England: Elsevier.

Johnson, R. L., Perea, M., \& Rayner, K. (2007). Transposed-letter effects in reading: Evidence from eye movements and parafoveal preview. Journal of Experimental Psychology: Human Perception and Performance, 33, 209-229.

Jordan, T. R. (1990). Presenting words without interior letters: Superiority over single letters and influence of postmask boundaries. Journal of Experimental Psychology: Human Perception and Performance, 16, 893-909.

Krueger, L. E. (1978). A theory of perceptual matching. Psychological Review, 85, 278-304.

Kučera, H., \& Francis, W. N. (1967). Computational analysis of presentday American English. Providence, RI: Brown University Press.

Lee, C. L., \& Estes, W. K. (1977). Order and position in primary memory for letter strings. Journal of Verbal Learning and Verbal Behavior, 16, 395-418.

Logan, G. D. (1996). The CODE theory of visual attention: An integration of space-based and object-based attention. Psychological Review, 103, 603-649.

Maddox, W. T., Prinzmetal, W., Ivry, R. B., \& Ashby, F. G. (1994). A probabilistic multidimensional model of location information. Psychological Research, 56, 66-77. 
McClelland, J. L., \& Rumelhart, D. E. (1981). An interactive activation model of context effects in letter perception: Part 1. An account of basic findings. Psychological Review, 88, 375-407.

Mozer, M. C. (1983). Letter migration in word perception. Journal of Experimental Psychology: Human Perception and Performance, 9, 531-546.

Mozer, M. C. (1987). Early parallel processing in reading: A connectionist approach. In M. Coltheart (Ed.), Attention and performance XII: The psychology of reading (pp. 83-104). Hillsdale, NJ: Erlbaum.

Norris, D. (2006). The Bayesian reader: Explaining word recognition as an optimal Bayesian decision process. Psychological Review, 113, 327-357.

Norris, D., \& Kinoshita, S. (2007, August). Slow slots with slops: Evidence for "slot-coding" of letter positions with positional noise. Paper presented at the meeting of the European Society for Cognitive Psychology, Marseille, France.

Nosofsky, R. M., \& Palmeri, T. J. (1997). An exemplar-based random walk model of speeded classification. Psychological Review, 104, 266-300.

O'Connor, R. E., \& Forster, K. I. (1981). Criterion bias and search sequence bias in word recognition. Memory \& Cognition, 9, 78-92.

Perea, M. (1998). Orthographic neighbors are not all equal: Evidence using an identification technique. Language and Cognitive Processes, 13, 77-90.

Perea, M., \& Acha, J. (2008). Vowel/consonant differences in the transposed-letter priming effect are task-dependent. Manuscript submitted for publication.

Perea, M., Acha, J., \& Fraga, I. (2008). Lexical competition is enhanced in the left hemisphere: Evidence from different types of orthographic neighbors. Brain and Language, 105, 199-210.

Perea, M., \& Carreiras, M. (1998). Effects of syllable frequency and syllable neighborhood frequency in visual word recognition. Journal of Experimental Psychology: Human Perception and Performance, 24, $134-144$.

Perea, M., \& Carreiras, M. (2006a). Do transposed-letter effects occur across lexeme boundaries? Psychonomic Bulletin \& Review, 13, 418-422.

Perea, M., \& Carreiras, M. (2006b). Do transposed-letter similarity effects occur at a prelexical phonological level? Quarterly Journal of Experimental Psychology, 59, 1600-1613.

Perea, M., Duñabeitia, J. A., \& Carreiras, M. (2008). Transposed-letter priming effects for close vs. distant transpositions. Experimental Psychology, 55, 397-406.

Perea, M., \& Estévez, A. (2008). Transposed-letter similarity effects in naming pseudowords: Evidence from children and adults. European Journal of Cognitive Psychology, 20, 22-46.

Perea, M., \& Lupker, S. J. (2003a). Does jugde activate COURT? Transposed-letter confusability effects in masked associative priming. Memory \& Cognition, 31, 829-841.

Perea, M., \& Lupker, S. J. (2003b). Transposed-letter confusability effects in masked form priming. In S. Kinoshita \& S. J. Lupker (Eds.), Masked priming: State of the art (pp. 97-120). Hove, England: Psychology Press.

Perea, M., \& Lupker, S. J. (2004). Can CANISO activate CASINO? Transposed-letter similarity effects with nonadjacent letter positions. Journal of Memory and Language, 51, 231-246.

Perea, M., Rosa, E., \& Gómez, C. (2005). The frequency effect for pseudowords in the lexical decision task. Perception \& Psychophysics, 67, 301-314.

Perry, C., Ziegler, J. C., \& Zorzi, M. (2007). Nested incremental modeling in the development of computational theories: The CDP + model of reading aloud. Psychological Review, 114, 273-315.

Plaut, D. C., McClelland, J. L., Seidenberg, M. S., \& Patterson, K. (1996). Understanding normal and impaired word reading: Computational principles in quasi-regular domains. Psychological Review, 103, 56-115.

Proctor, R. W., \& Healy, A. F. (1985). Order-relevant and order-irrelevant decision rules in multiletter matching. Journal of Experimental Psychology: Learning, Memory, and Cognition, 11, 519-537.

Proctor, R. W., \& Healy, A. F. (1987). Task-specific serial position effects in comparisons of multiletter strings. Perception \& Psychophysics, 42, 180-194.
Ratcliff, R. (1978). A theory of memory retrieval. Psychological Review, $85,59-108$

Ratcliff, R. (1981). A theory of order relations in perceptual matching. Psychological Review, 88, 552-572.

Ratcliff, R. (1985). Theoretical interpretations of speed and accuracy of positive and negative responses. Psychological Review, 92, 212-225.

Ratcliff, R. (1987). Order information and distributed memory models. In Proceedings of the Ninth Annual Conference of the Cognitive Science Society (pp. 474-486). Hillsdale, NJ: Erlbaum.

Ratcliff, R., Gomez, P., \& McKoon, G. (2004). A diffusion model account of the lexical decision task. Psychological Review, 111, 159-182.

Ratcliff, R., \& Hacker, M. J. (1981). Speed and accuracy of same and different responses in perceptual matching. Perception \& Psychophysics, 30, 303-307.

Ratcliff, R., \& McKoon, G. (1997). A counter model for implicit priming in perceptual word identification. Psychological Review, 104, 319-343.

Ratcliff, R., \& McKoon, G. (in press). The diffusion decision model: Theory and data for two-choice decision tasks. Neural Computation.

Ratcliff, R., McKoon, G., \& Verwoerd, M. (1989). A bias interpretation of facilitation in perceptual identification. Journal of Experimental Psychology: Learning, Memory, and Cognition, 15, 378-387.

Ratcliff, R., \& Rouder, G. (1998). Modeling response times for decisions between two choices. Psychological Science, 9, 347-356.

Ratcliff, R., \& Rouder, J. F. (2000). A diffusion model account of masking in two-choice letter identification. Journal of Experimental Psychology: Human Perception and Performance, 26, 127-140.

Ratcliff, R., Van Zandt, T., \& McKoon, G. (1999). Connectionist and diffusion models of reaction time. Psychological Review, 106, 261-300.

Rayner, K., Inhoff, A. W., Morrison, R. E., Slowiaczek, M. L., \& Bertera, J. H. (1981). Masking of foveal and parafoveal vision during eye fixations in reading. Journal of Experimental Psychology: Human Perception and Performance, 7, 167-179.

Rayner, K., Liversedge, S. P., White, S. J., \& Vergilino-Perez, D. (2003). Reading disappearing text: Cognitive control of eye movements. Psychological Science, 14, 385-388.

Rayner, K., \& Pollatsek, A. (1981). Eye movement control during reading: Evidence for direct control. Quarterly Journal of Experimental Psychology: Human Experimental Psychology, 33(A), 351-373.

Rayner, K., White, S. J., Johnson, R. L., \& Liversedge, S. P. (2006). Raeding wrods with jubmled letetrs: There's a cost. Psychological Science, 17, 192-193.

Reichle, E. D., Pollatsek, A., Fisher, D. L., \& Rayner, K. (1998). Toward a model of eye movement control in reading. Psychological Review, 105, $125-157$.

Rumelhart, D. E., \& McClelland, J. L. (1982). An interactive activation model of context effects in letter perception: Part 2. The contextual enhancement effect and some tests and extensions of the model. Psychological Review, 89, 60-94.

Schoonbaert, S., \& Grainger, J. (2004). Letter position coding in printed word perception: Effects of repeated and transposed letters. Language and Cognitive Processes, 19, 333-367.

Seidenberg, M. S., \& McClelland, J. L. (1989). A distributed, developmental model of word recognition and naming. Psychological Review, 96, 523-568.

Thapar, A., Ratcliff, R., \& McKoon, G. (2003). A diffusion model analysis of the effects of aging on letter discrimination. Psychology and Aging, $18,415-429$.

Treisman, A., \& Schmidt, H. (1982). Illusory conjunctions in the perception of objects. Cognitive Psychology, 14, 107-141.

Van Assche, E., \& Grainger, J. (2006). A study of relative-position priming with superset primes. Journal of Experimental Psychology: Learning, Memory, and Cognition, 3, 399-415.

Van Oeffelen, M. P., \& Vos, P. G. (1982). Configurational effects on the 
enumeration of dots: Counting by groups. Memory \& Cognition, 10, 396-404.

Van Oeffelen, M. P., \& Vos, P. G. (1983). An algorithm for pattern description on the level of relative proximity. Pattern Recognition, 16, 341-348.

White, S. J., Johnson, R. L., Liversedge, S. P., \& Rayner, K. (in press). Eye movements when reading transposed text: The importance of wordbeginning letters. Journal of Experimental Psychology: Human Perception and Performance.

Whitney, C. (2001). How the brain encodes the order of letters in a printed word: The SERIOL model and selective literature review. Psychonomic Bulletin \& Review, 8, 221-243.

Whitney, C. (in press). A comparison of the SERIOL and SOLAR theories of letter-position encoding. Brain and Language.

Whitney, C., \& Berndt, R. S. (1999). A new model of letter string encoding: Simulating right neglect dyslexia. Progress in Brain Research, 121, 143-163.

Whitney, C., \& Lavidor, M. (2005). Facilitative orthographic neighborhood effects: The SERIOL model account. Cognitive Psychology, 51, $179-213$.

\section{Appendix A}

\section{Methods and Results}

This appendix includes the Method and Results sections for all experiments.

\section{General Method}

\section{Participants}

Northwestern University (Evanston, IL) undergraduates participated in these experiments. There were 18 participants in Experiment 1a, 17 in Experiment 1b, 24 in Experiment 2, 20 in Experiment 3, 22 in Experiment 4, and 32 in Experiment 5. None of the participants took part in more than one experiment, and all of them were fulfilling a requirement for an Introduction to Psychology class.

\section{Materials}

For all experiments, we created sets of similar stimuli by rearranging the letters in either pseudowords or English words. The pseudowords (1,380 of them) were created by substituting the vowels in an English word with other vowels. Each target stimulus (or any of the items generated by it) was presented only once. Table 1 in the main text shows what types of stimuli were used in each of the experiments. During the generation of items, vowels were always replaced by vowels, and consonants were always replaced by consonants in the replacement conditions. Of course, this produced an unavoidable confound - transpositions might alter the consonantvowel structure to a higher degree than replacement items- - however, we do not believe that this affected the results in a fundamental way.

Experiment 1. In Experiment 1, the alternatives in the forcedchoice task were a pseudoword and a similar letter string that was generated by either transposing two letters, replacing one letter, or replacing two letters (see Table 1 in the main text). There were 23 types of stimuli in Experiment 1a and 17 in Experiment 1b. In Experiment 1a, there were 15 experimental blocks with 92 trials each, and in Experiment $1 \mathrm{~b}$, there were 18 experimental blocks with 68 trials each.

Experiment 2. There were two sets of materials. The first set included 814 five-letter words selected from the Kučera and Francis (1967) list. The words had a mean frequency of occurrence of 68 per million (range: 4-2,714). For a given word, the similar nonword items could be a transposed-letter item, a single replacement item, or a double replacement item. Transpositions, replacements, and single replacements were constructed the same way as in Experiment 1a. A second set of 201 word-word pairs was also selected from the Kučera and Francis (1967) norms. In these pairs, words shared all the letters except for two that were transposed (e.g., adjacent transposed-letters pairs such as trial-trail or nonadjacent transposed-letters pairs such risen-siren). Note that we did not use replacement items because of the very low number of words that can generate both a replaced-letter and a transposed-letter word neighbor. The mean frequency of the words was 36 and 20 per million for the adjacent transposed-letters and the nonadjacent transposed-letters words, respectively. Given the small number of word-word pairs of five letters, we also used wordword pairs of six and seven letters (making the mean letter length 5.6 letters and the range 5-7). Each participant was shown 736 trials randomly chosen from the word-nonword set (all five letters long and counterbalanced across participants) and 192 (randomly selected from the set of 201) trials from the word-word set. If one participant was presented with a word target in the word-nonword pair, the next one would be shown the nonword as a target. Overall, there were eight experimental blocks with 116 trials each, for a total of 928 trials.

Experiment 3. The pseudoword list was used in Experiment 3, in which there were 23 conditions that included single letter replacement conditions, adjacent letter transposition conditions, letter migration conditions, and orthographic controls for the letter migration conditions. For example, assuming $\mathrm{ABCDE}$ as one of the alternatives, in the letter migration conditions the other alternatives were BCADE, ACDBE, CABDE, ABDEC, ADBCE, AB$\mathrm{ECD}$, and $\mathrm{AEBCD}$; and an orthographic controls for the lettermigration items were BCXDE, ACDXE, XABDE, ABDEX, $\mathrm{AXBCE}, \mathrm{ABXCD}$, and $\mathrm{AXBCD}$. Overall, there were 13 experimental blocks with 92 trials each (four items of each of the 23 conditions per block), for a total of 1,196 trials.

Experiment 4. The pseudoword list was used in Experiment 4. Thirty-seven conditions were used in this experiment. For a stimulus without any repeated letters (e.g., ABCDE), the foils could be nonwords with a letter repeated in an adjacent or nonadjacent position (ABBDE, ABCCE, ABCDD, ABADE, ABCBE, ABCDC, and AB$\mathrm{CD} B$ ). The strings with repeated letters were also used as targets, with the foils being strings with no repeated letters. The third type of item consisted of foils and targets with repeated letters (12 conditions: ABBDE vs. $\mathrm{ADBBE}, \mathrm{ABCCE}$ vs. $\mathrm{ACCBE}, \mathrm{ABCDD}$ vs. $\mathrm{ABDDC}$, ABADE vs. BADAE, ABCBE vs. ACBEB, and ABCDC vs, ACBCD). In addition, to further constrain the model, we included transposed-letter items and single replacement items, as in the previ- 
ous experiments. For each participant, 1,249 pairs were selected. Overall, there were 13 experimental blocks with 96 trials each.

Experiment 5. The pseudoword list was used in Experiment 5. In addition to transposed-letter and single replacement letter items, this experiment featured the insertion of letters; if one of the alternatives was $\mathrm{ABCDE}$, then the other alternative was $\mathrm{AXB}$ CDE, ABXCDE, ABCXDE, ABCDXE, or ABCDEX. For each participant, 1,080 pairs were randomly selected. There were 15 experimental blocks with 72 trials each.

\section{Procedure}

Participants were tested in groups of one to three. PC-compatible computers controlled presentation of the stimuli and recording of response times. Stimuli were presented on a 15 -in. computer monitor in 24-point BrHand font (similar to nonproportional Courier fonts). On each trial, a fixation point $(\mathrm{a}+\mathrm{sign})$ was presented for $500 \mathrm{~ms}$ on the center of the screen. Then, an uppercase letter string was presented on the center of the screen for $60 \mathrm{~ms}$, followed by a mask with an image composed by random segments of letters. Two uppercase letter strings were presented two lines below the mask, one to the left and the other to the right of the location where the stimulus test had been presented (see Figure 2 in the main text). One of the alternatives was the stimulus item, and the other was a foil. Participants were told to indicate which alternative was the stimulus item that had been presented briefly. The order of presentation was randomized across participants, and in all experiments, each alternative was the correct response in equal number of trials.

\section{Results for All Experiments}

\section{Experiment 1}

In this and in subsequent experiments, responses with latencies less than $250 \mathrm{~ms}$ or greater than 1,600 ms were excluded from the analyses (less than $1 \%$ of all responses). Response probabilities were calculated for each participant for each condition, and then, they were averaged across participants.

Table 2 in the main text shows the response probabilities for each condition. In this and in subsequent experiments, unless otherwise noted, all significant effects had $p$ values of less than .05. For Experiment 1a, we first conducted an analysis of variance (ANOVA) to examine the effect of position across the five conditions with a single letter replacement. The results showed a significant effect of position, $F(4,68)=43.94$, which was caused mainly by the elevated proportion of correct responses when the mismatch occurred in the initial letter position. Second, we conducted an ANOVA to examine, for adjacent transpositions/replacements, the effects of type of trial (transposition or replacement) and letter position(s) being manipulated (first/second, second/third, third/fourth, and fourth/fifth). The ANOVA showed an effect of letter position, $F(3,51)=70.54$; type of trial, $F(1,17)=89.61$; and more important, an interaction between the two factors, $F(3,51)=14.10$ : The transposed-letter effect was smaller when the transposition involved the initial letter position. Third, we conducted a parallel ANOVA with nonadjacent letter positions (one letter in between) to examine the effects of type of trial (transposition or replacement) and letter position(s) being manipulated (first/third, second/fourth, and third/fifth). Again, the ANOVA showed an effect of letter position, $F(2,34)=78.87$; type of trial, $F(1$, $17)=57.48$; and more important, an interaction between the two factors, $F(2,34)=11.88$ : The transposed-letter effect was smaller when the transposition involved the initial letter position. Fourth, we conducted a parallel ANOVA with nonadjacent letter positions (two letters in between) to examine the effects of type of trial (transposition or replacement) and letter position(s) being manipulated (first/fourth, second/fifth). Again, the ANOVA showed an effect of letter position, $F(1,17)=92.37$; type of trial, $F(1,17)=14.02$; and more important, an interaction between the two factors, $F\left(\begin{array}{ll}1,1 & 7)=4.77 \text { : The }\end{array}\right.$ transposed-letter effect was smaller when the transposition involved the initial letter position.

We should also note that, across all conditions involving the manipulation of two letters in Experiment 1a, transposing letters yielded lower discriminability values than replacing letters, replicating previous research (Perea \& Lupker, 2003b; Ratcliff, 1981, 1985; Ratcliff \& Hacker, 1981); for all but three conditions, this difference was highly significant $(p<.005)$. For three conditions in Experiment 1a, the difference between transposition and replacement trials was not significant (transpositions of Letters 1 and 2, 1 and 3, and 1 and 4), which was probably due to near-ceiling levels of performance in the conditions that involved changes in the first letter position. Although this level of accuracy is not surprising given the importance of the initial letter in visual word recognition, it could be argued that this pattern was the result of the participants paying more attention to the first letter position. Experiment $1 \mathrm{~b}$ reduced the number of conditions by eliminating most of the transposition/replacement conditions involving the first letter position to examine whether the results would be similar when participants were discouraged (via the proportion of items) from attending to the first position of the string.

For Experiment 1b, we followed the same strategy as in Experiment 1a. That is, we first conducted an ANOVA to examine the effect of position across the four conditions with a single letter replacement. The results showed a significant effect of position, $F(3,48)=10.99$, which was caused mainly by the elevated proportion of correct responses when the mismatch occurred in the initial letter position. Second, we conducted an ANOVA to examine, for adjacent transpositions/replacements, the effects of type of trial (transposition or replacement) and letter position(s) being manipulated (second/third, third/fourth, and fourth/fifth). The ANOVA showed a significant effect of type of trial, $F(1,16)=$ 105.53 , and also an interaction between the two factors, $F(2,32)=$ 3.92. Third, we conducted a parallel ANOVA with nonadjacent letter positions (one letter in between) to examine the effects of type of trial (transposition or replacement) and letter position(s) being manipulated (second/fourth, third/fifth). The ANOVA showed an effect of letter position, $F(1,16)=5.64$, and type of trial, $F(1,16)=70.95$. Fourth, we conducted a parallel ANOVA with nonadjacent letter positions (two letters in between) to examine the effects of type of trial (transposition or replacement) for positions second/fifth. Again, the ANOVA showed an effect of letter transposition, $F(1,16)=18.77$.

What we should also note is that, in Experiment $1 \mathrm{~b}$, all the pairwise $t$ tests between the transposed-letter conditions and their replacement controls were highly significant (the range of $t$ values was from 4.33 to 9.51 , and all $p$ s were $<.001)$. It is interesting to note that in these experiments, changes in the (final) fifth letter position (e.g., replacement of Letter 5, replacement of Letters 4 and 5, and transposition of Letters 4 and 5) yielded performance levels similar to conditions with changes in the internal letter positions. 


\section{Experiment 2}

Table 4 and Figure 4 in the main text show the response probabilities for each condition. Response probabilities were calculated across individuals and were submitted to ANOVAs with three within-participant factors: lexical status of the target (e.g., word or nonword), type of trial (transposition or replacement), and letter position(s) being manipulated (e.g., 1, 1 and 2, etc.).

There was a large effect of lexical status of the target string on accuracy, $F(2,23)=28.06$. Responses were more accurate when the targets were words than when they were nonwords. The patterns of results within the different types of trial, however, are very similar; the average accuracy rates for the transposed-letter stimuli had a correlation of $r=.976, t(5)=10.06$, between the nonword-word and the word-word trials; $r=.988, t(5)=14.27$, between the word-nonword and the word-word trials; and $r=.940, t(21)=12.61$, between the nonword-word and the word-nonword trials. A more detailed discussion of the implications of the lexicality effects will be presented in conjunction with a discussion of the parameter estimates for this experiment. Also, as in Experiment 1, replacement items were more accurate than transposition items, $F(1,23)=91.94$, but as noted earlier, the position of the replacements affected the size of the effect, as is indicated by the significant interaction between letter position and replacement/transposition, $F(1,23)=91.99$.

\section{Experiment 3}

Response probabilities (shown in Table 5 in the main text) were calculated across individuals. As in the previous experiments, transposition trials were more difficult than replacement trials, as shown by pairwise $t$ tests between the transposition letter items and the single replacements, which were all significant (even that for transposition of Letters 1-2 and replacement of Letter 1), and the overall pattern of results was similar to those in previous experiments. In addition, migration trials were slightly more difficult than their orthographic controls (see Figure 5 in the main text). However, $t$ tests for migrated letters versus their orthographic controls were significant only for the migration from Letter 2 to Position 4, $t(19)=3.00$; Letter 4 to Position 2, $t(19)=2.56$; and Letter 5 to Position 3, $t(19)=3.17$. Again, when the first letter was manipulated in any way, the probability of a correct response was high, and differences among type of items were small.

\section{Experiment 4}

Table 6 and Figure 6 in the main text show the response probabilities for each condition in this experiment. Note that in this experiment, there are no explicit orthographic controls because there are enough conditions to constrain the model. Repeated letters had a large effect on accuracy: For items in which the target had a repeated letter and the foil did not, performance was worse (accuracy was .684 for adjacent letter repetition and .681 for nonadjacent letter repetition) than for items in which the foil and not the target had a repeated letter (accuracies of .807 and .779 for items with foils that included adjacent letter repetitions and nonadjacent letter repetitions, respectively, $p<.001$ ). In addition, accuracy for trials in which both the target and the foil included repeated letters was about halfway between conditions that had either a repeated letter in the target or a repeated letter in the foil. The accuracy values for items with targets and foils with repeated letters were .786 for adjacent letter repetitions and .720 for nonadjacent letter repetitions. This shows that there was a bias toward choosing the alternative without the repetition. As in the previous experiments, transposition trials were more difficult than replacement trials, and when the first letter was manipulated in any way, the probability of correct responses was high, and differences among items types were reduced.

\section{Experiment 5}

The pattern of results for replacement and transposed letters is the same as in the previous experiments (see Table 7 and Figure 8 in the main text). The accuracy of items of unequal letter length is between that for replaced and transposed-letter items, $F(2,28)=$ 18.365. The position of the insertion of the letter yielded significant differences, $F(4,28)=6.344$.

For the inserted letter conditions, accuracy decreased from the first position, as the position of the inserted letter moved toward the right, and then it was greater again for the last position, Position 4 versus 5 , $t(28)=3.338$; Position 1 versus $3, t(28)=4.497$. In addition, insertion of letters in the target produced lower accuracies than insertion of letters in the foil only for the rightmost letter positions; for Position 4, $t(28)=1.815$, and for Position $5, t(28)=2.346$.

\section{Appendix B}

\section{Masked Priming and the Overlap Model}

One central technique for studying the processes underlying visual word recognition has been the masked priming paradigm (Forster \& Davis, 1984). As Grainger (2008) indicated, "in the last two decades masked priming has become a key tool for studying all aspects of visual word recognition, using both behavioral measures of performance and also more direct measures of brain activity" (p. 8). In this technique, a forward-masked, lowercase prime is presented briefly (30-66 ms) and is subsequently replaced by the uppercase target. When used in the context of the lexical decision task-the most popular laboratory word identification task-participants have to decide whether the uppercase item is a word or a nonword. A manipulation that is currently popular is one in which the relationship between the letters in the target are altered by replacement or trans- position to form the prime (e.g., Andrews, 1996; Castles et al., 2003; Christianson, Johnson, \& Rayner, 2005; Forster et al., 1987; Guerrera \& Forster, 2007; Perea \& Carreiras, 2006a, 2006b; Perea \& Lupker, 2003b; Schoonbaert \& Grainger, 2004). Then, these various conditions are used to test the word-recognition models.

It seems natural that the overlap model should apply to data from these studies. There are two limitations, though. First, the masked priming effects obtained are very small, of the order of 10-25 ms. This means that, in any experiment, all one really knows is whether a mean reaction time (RT) for a condition is significantly different from a control condition or not. Anything finer grained is extremely difficult to detect. For example, Perea, Duñabeitia, and Carreiras (2008) failed to find a significant dif- 
ference between the transposed-letter priming effect when the nonadjacent internal transposition had one letter between the two transposed letters and when the nonadjacent internal transposition had two letters between the two transposed letters. This failure to obtain a difference was probably due to lack of power at detecting a very small effect with the masked priming paradigm. This is in contrast to our identification paradigm, in which differences in accuracy are large and graded and differences among conditions are easily measurable. Second, one major problem with the masked priming task is that currently there is no good model of the decision process that accounts for accuracy and RT distributions for correct and error word and nonword responses. Furthermore, masked priming effects for words in lexical decision differ for word and nonword primes (e.g., Carreiras \& Perea, 2002), which suggests that one may need to have a model of lexical decision. We can imagine an application of the diffusion model (Ratcliff, 1978, 1981; Ratcliff \& McKoon, in press; Ratcliff \& Rouder, 1998;
Ratcliff, Van Zandt, \& McKoon, 1999), as in Ratcliff, Gomez, and McKoon (2004) and Gomez, Ratcliff, and Perea (2007), that might be able to be applied, but this is beyond the scope of this article.

One major difference between the masked priming task and our matching task is that in masked priming, there is no effect of the prime on nonword responses in most of the masked priming experiments, whereas in the identification paradigm, there are large effects on nonword identification - in fact, most of our experiments used nonword targets. We attribute this to the fact that in an identification task, participants have to explicitly process the whole letter string and decide which of two targets it matches, but in priming, the data suggest that any test string that is nonwordlike can be rejected without much processing of the individual letters. There are other effects of nonword primes on word identification in lexical decision. If the nonwords are wordlike, RT is slowed, and accuracy is reduced for word targets (e.g., Ratcliff et al., 2004). Furthermore, it is important to note that masked priming effects may differ depending on the nature of the experimental task; as indicated by Norris

Table B1

Masked Priming Effects and Overlap Values for Recently Published Articles

Davis \& Bowers (2006) Experiments 2 \& 3

\begin{tabular}{lccccc}
\hline & \multicolumn{2}{c}{ Target } & \multicolumn{3}{c}{ Prime conditions } \\
\cline { 2 - 6 } & ANKLE & AXKLE & ANKXE & AKXLE & ANXKE \\
\cline { 2 - 6 } Priming effect $(\mathrm{ms})$ & 1.57 & 30 & 1.31 & 31 & 18 \\
Overlap value & & 1.31 & 1.26 & 1.26 \\
\hline
\end{tabular}

Guerrera \& Forster (2007) Experiment 1

\begin{tabular}{lccc}
\hline & Target & \multicolumn{2}{c}{ Prime conditions } \\
\cline { 2 - 3 } & 12345678 & 13254768 & 21345687 \\
\cline { 2 - 4 } Priming effect $(\mathrm{ms})$ & 45 & 30 & 23 \\
Overlap value & 2.35 & 2.05 & 1.90 \\
\hline
\end{tabular}

Guerrera \& Forster (2007) Experiment 2

\begin{tabular}{lcccc}
\hline & Target & \multicolumn{2}{c}{ Prime conditions } \\
\cline { 2 - 5 } & $\frac{13254768}{12345678}$ & 16 & 12436587 & 21436578 \\
\cline { 2 - 5 } Priming effect (ms) & 2.35 & $2.05^{\mathrm{a}}$ & 29 & 16 \\
Overlap value & & 1.05 & 2.80 \\
\hline
\end{tabular}

Guerrera \& Forster (2007) Experiment 3

\begin{tabular}{lcccc}
\hline & \multicolumn{2}{c}{ Target } & \multicolumn{2}{c}{ Prime conditions } \\
\cline { 2 - 5 } & 12345678 & 27 & 43218765 & 21436587 \\
\cline { 2 - 5 } Priming effect $(\mathrm{ms})$ & 2.35 & 2.05 & 1 & 1 \\
Overlap value & & 0.96 & $1.69^{\mathrm{a}}$ \\
\hline
\end{tabular}

Grainger, Granier, Farioli, Van Assche, \& van Heuven (2006) Experiments 2, 3, \& 5

\begin{tabular}{lcccc}
\hline & Target & \multicolumn{2}{c}{ Prime conditions } \\
\cline { 2 - 5 } & $\frac{1234567}{n}$ & 12345 & 34567 & 26 \\
\cline { 2 - 5 } $\begin{array}{l}\text { Priming effect (ms) } \\
\text { Overlap value }\end{array}$ & 2.10 & 37 & 1.31 & 23 \\
\hline
\end{tabular}

Note. All the priming effects are significant except the 43218765 and 21436587 conditions in Guerrera and Forster (2007). The overlap model standard deviations in the letters were 0.7 for the first letter and 1.5 for the remaining letters.

${ }^{a}$ Conditions in which the overlap model would predict larger priming effects. 
and Kinoshita (2007), masked priming effects for nonwords can be easily obtained with a same-different task but not with the lexical decision task (see also Perea \& Acha, 2008, for similar results). This suggests that modeling masked priming effects in conjunction with nonword effects will not be simple.

However, it is fair to ask how well the overlap model predicts the differences in word target conditions for the various transposition manipulations to see whether it could be a candidate to play a role in word identification in this masked priming paradigm. To do this, we selected eight experiments from three recent articles from the literature that have examined transpositions in masked priming (Davis \& Bowers, 2006; Grainger, Granier, Farioli, Van Assche, \& van Heuven, 2006; Guerrera \& Forster, 2007). We generated overlap values for the same conditions using a minimal version of the overlap model, with standard deviations in the letters that were 0.7 for the first letter and 1.5 for the remaining letters. The orthographic similarity (overlap) between the prime and the targets was calculated using Equation 1 from the main text. These are displayed in Table B1. For this simple version of the model with parameter values not generated by fits to data, the overlap model predicts priming effects that are consistent with the small priming effects obtained in the experiments, with only two exceptions. There are two things to say about the exceptions: First, the model was not fit, so idiosyncratic values of the standard deviations might alter the predictions somewhat; second, the size of the masked priming effects are small, and differences in the patterns of results might be obtained upon replication.

Thus, the overlap model may work as a front end of a fully implemented model of visual word recognition, and hence, it is not restricted to the specific characteristics of the matching paradigm. One example is the Bayesian reader model (Norris, 2006). As we indicate in the main text, the Bayesian reader model can easily use the overlap module as a front end of the model-instead of the position-specific coding scheme of the original implementation of the model (see Norris \& Kinoshita, 2007).

Appendix C

Code in R for the Overlap Model

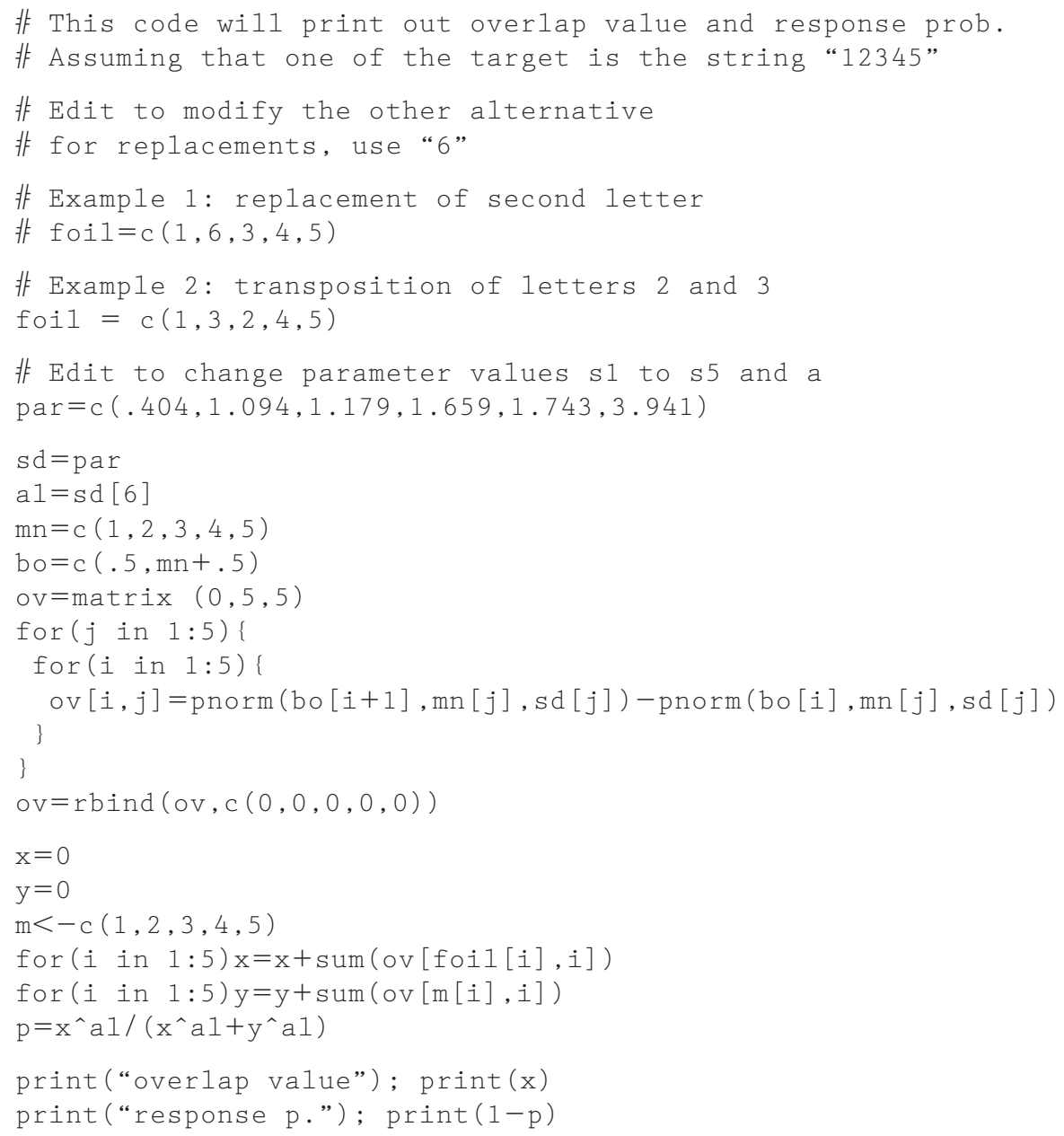

